CORREA, Carlos. "Más Más allá de la regla de exclusión: prohibiciones probatorias en el Derecho chileno - con especial referencia al Derecho alemán -"

Polít. crim. Vol. 13, N 25 (Julio 2018) Art. 4, pp. 144-174.

[http://www.politicacriminal.cl/Vol_13/n_25/Vol13N25A4.pdf]

\title{
Más allá de la regla de exclusión: prohibiciones probatorias en el Derecho chileno - con especial referencia al Derecho alemán -
}

\section{Beyond the Exclusionary Rule: Evidence restrictions in Chilean Law - Specially referring to German Law -}

\author{
Carlos Correa Robles* \\ LL.M. y estudiante de Doctorado, Freie Universität Berlin, \\ Profesor de Derecho Procesal, Universidad Adolfo Ibáñez \\ c.correa@uai.cl
}

\section{Resumen}

El presente artículo analiza distintos problemas referidos al tratamiento de la llamada "prueba ilícita" en el derecho chileno, que exceden el ámbito de aplicación de la regla de exclusión contemplada en el art. 276 inc. $3^{\circ} \mathrm{CPP}$. Punto de partida del trabajo corresponde al análisis del modelo de "prohibiciones probatorias" desarrollado en Alemania. A partir del estudio del sistema alemán, se intenta dar respuesta a las diversas problemáticas que la regulación chilena presenta en relación al tratamiento de la "prueba ilícita" en la etapa de investigación y de juicio oral.

\section{Palabras clave}

Prueba ilícita, regla de exclusión, prohibiciones probatorias, proceso penal.

\begin{abstract}
This article analyzes a number of problems connected with what is known as "illegally or wrongful obtained evidence" in the Chilean legal system. These problems do not fit the scope of application of the exclusionary rule established in article 276, 3rd paragraph of the Chilean Criminal Procedure Code. The starting point of this work is the analysis of the "evidence restrictions" model developed in Germany. From the study of the German legal system, the article aims to provide an answer to the diverse problems that Chilean regulation has facing "illegally or wrongful obtained evidence" during the investigation and trial.
\end{abstract}

\section{Keywords}

Illegally or wrongful evidence, exclusionary rule, evidence restrictions, criminal procedure.

\section{Introducción}

Habiendo transcurrido más de 15 años desde la promulgación del Código Procesal Penal, resulta incontrovertible que el modelo allí instaurado constituyó un hito fundamental en el proceso de reformas a la justicia emprendido por el Estado de Chile tras el retorno de la democracia. En concreto, la reforma al sistema de enjuiciamiento criminal supuso dejar atrás un modelo obsoleto, ineficiente, carente de imparcialidad y en el cual el imputado era

\footnotetext{
* Agradezco los valiosos comentarios, sugerencias y correcciones efectuados por los profesores Alberto Pino y Javier Wilenmann, así como por parte de los dos árbitros anónimos.
} 
Polít. crim. Vol. 13, № 25 (Julio 2018) Art. 4, pp. 144-174.

[http://www.politicacriminal.cl/Vol_13/n_25/Vol13N25A4.pdf]

considerado un objeto del proceso, más no un sujeto de derechos. En efecto, la estructura misma del sistema inquisitivo consagrado en el Código de Procedimiento Penal impedía resguardar adecuadamente aquellas garantías consagradas en la Constitución Política de 1980 y en diversos Tratados Internacionales de Derechos Humanos, dejando al imputado en una situación desmedrada frente al actuar de los órganos persecutores.

A este respecto, una de las principales innovaciones introducidas al proceso penal el año 2000, consistió en la incorporación -por vez primera en nuestra historia legislativa- de una regla de exclusión de prueba, establecida en el art. 276 CPP. Dicha disposición permite a los intervinientes, o bien al juez de garantía actuando de oficio, ${ }^{1}$ excluir del juicio oral en la audiencia de preparación del mismo, aquellos elementos probatorios contenidos en la(s) acusación(es) que resultaren impertinentes, dilatorios, sobreabundantes, que tuvieren por objeto acreditar hechos públicos y notorios, que provinieren de actuaciones o diligencias declaradas nulas, o bien, como afirma la última parte del inciso $3^{\circ}$, "que hubiesen sido obtenidos con inobservancia de garantías fundamentales".

La incorporación de una regla de exclusión de prueba obtenida con vulneración de garantías fundamentales, significó un punto de inflexión en nuestra historia legislativa, que permitió a los tribunales distanciarse de la práctica jurisprudencial previa, mantenida invariablemente en los 100 años de vigencia del proceso inquisitivo, mediante la cual un tratamiento diferenciado de la prueba recabada con infracción a reglas de obtención probatoria fue sistemáticamente ignorado por nuestros tribunales. ${ }^{2}$

Si bien la introducción en el proceso penal de una regla de exclusión de prueba permitió dar solución a importantes problemas generados a partir obtenciones probatorias atentatorias de garantías fundamentales, el tratamiento de la llamada "prueba ilícita" en el procedimiento ordinario fuera de la audiencia de preparación del juicio oral, no se encuentra exento de dificultades. Es precisamente el análisis de los casos en los cuales el juez debe resolver en base a prueba ilícitamente obtenida, y cuya exclusión no resulta materialmente procedente o temporalmente pertinente, aquellos que suscitarán nuestra atención.

A este respecto, cabe en primer término hacer referencia a los evidentes problemas que genera la ausencia de tratamiento legal respecto de la prueba ilícita en la etapa de investigación. A este respecto: ¿puede el juez de garantía al tomar contacto con elementos probatorios ilícitamente obtenidos, por ejemplo al momento de resolver una solicitud de medidas cautelares, excluirlos? ¿Debe por el contrario valorarlos positivamente en todo caso, aduciendo que no es la oportunidad procesal pertinente para discutir su exclusión? ¿Puede el juez excluir de su valoración dichos elementos probatorios al momento de resolver? En caso afirmativo ¿bajo qué fundamento?

\footnotetext{
${ }^{1}$ En este sentido: CERDA SAN MARTIN, Rodrigo, "La prueba ilícita y la regla de exclusión", Revista de la justicia penal, $\mathrm{n}^{\circ} 6$ (2010), pp. 99-176, p. 151 y s.; HERNANDEZ BASUALTO, Héctor, Exclusión de la prueba ilícita en el nuevo proceso penal chileno, 2a Reimpresión, Santiago: Universidad Alberto Hurtado, 2005, p. 72 y s.; HORVITZ LENNON, María Inés; LOPEZ MASLE, Julián, Derecho procesal penal, Tomo II, Santiago: Jurídica de Chile, 2004, p. 213. En contra: ARMENTA DEU, Teresa, "La verdad en el filo de la navaja (nuevas tendencias en materia de prueba ilícita)”, Ius et Praxis, Vol. 13, N 2 (2007), pp. 345-377, p. 371, para quien la exclusión de prueba sólo puede efectuarse previa iniciativa de alguno de los intervinientes.

2 Cfr. BOFILL GENZSCH, Jorge, Die Beweisverbote im chilenischen Strafprozess, Friedrich-AlexanderUniversität zu Erlangen-Nürnberg, inédito, 1988, p. 110 y s.; DIAZ GARCIA, Luis, "Derechos fundamentales y prueba ilícita en el nuevo proceso penal chileno", en: COLOMA CORREA, Rodrigo (Coord.), La prueba en el nuevo proceso penal oral, Santiago: Lexis Nexis, 2003, pp. 129-160, p. 136.
} 
146 CORREA, Carlos. "Más Más allá de la regla de exclusión: prohibiciones probatorias

en el Derecho chileno - con especial referencia al Derecho alemán -".

Similares dudas pueden surgir en la etapa de juicio oral: ¿qué tratamiento debe dar el tribunal a aquella prueba obtenida mediante infracción de garantías, erróneamente incorporada en el auto de apertura? ¿Puede excluirla? ¿Debe el tribunal de juicio oral necesariamente valorar positivamente dicha prueba? ¿Debe el juez hacer caso omiso del error u omisión cometido en la audiencia de preparación?

Punto de partida de la presente investigación lo constituye el tratamiento de las llamadas prohibiciones probatorias en el derecho procesal penal alemán. Ante la ausencia en dicho ordenamiento de una regla general de exclusión de prueba, equiparable a nuestro art. 276 inc. $3^{\circ} \mathrm{CPP}$, desde hace más de 100 años la doctrina y la jurisprudencia alemana han venido desarrollando profusamente una teoría general, dirigida a limitar los alcances de la regla de la libre valoración de la prueba establecida en el § 261 de la Ordenanza Procesal Penal alemana (StPO), reconociendo la existencia de verdaderas prohibiciones de valoración de prueba, fundamentadas principalmente a partir de infracciones a reglas de obtención de prueba cometida por los órganos persecutores.

De este modo, y a diferencia de lo que sucede en nuestro sistema, el tratamiento de la llamada "prueba ilícita" en el derecho alemán se ha desarrollado no a través de una decisión del legislador, sino gracias a un desarrollo dogmático reconocido jurisprudencialmente, cuyos aspectos esenciales podrían -mutatis mutandi- resultar útiles para resolver algunas dudas que genera de lege lata el tratamiento de los problemas ya enunciados en el ordenamiento chileno. A esto nos enfocaremos en los siguientes acápites.

\section{Las prohibiciones de prueba en el Derecho alemán}

Como ya se mencionó, la StPO no ha consagrado expresamente una regla general de exclusión de prueba como la regulada en el art. 276 inc. $3^{\circ} \mathrm{CPP}$. Lo anterior no ha sido óbice para que la doctrina y jurisprudencia de dicho país reconozcan (hoy en día, unánimemente) la existencia de las denominadas prohibiciones probatorias (Beweisverbote). Bajo dicho concepto general, se entiende la proscripción de desarrollar determinadas actividades probatorias dirigidas a la acreditación de los hechos en el proceso penal. ${ }^{3}$

El origen de dicho concepto en Alemania, y en general de la discusión sobre el tratamiento de la prueba obtenida con infracción de reglas, encuentra su punto de partida en la clase inaugural dictada por Ernst Beling, realizada con ocasión de su nombramiento como docente en la Universidad de Tübingen el año 1903, denominada "Las prohibiciones de prueba como límites a la averiguación de la verdad en el proceso penal"4 ("Die Beweisverbote als Grenze der Wahrheitsforschung im Strafprozess"). La elección de dicho tema por parte de Beling, cuya motivación se desconoce, constituyó el punto de partida de una fructífera discusión desarrollada en dicho país respecto del alcance y límites a la regla de libre valoración de la prueba antes mencionada, cuyos contornos y límites siguen siendo incluso hoy en día tema de intenso

\footnotetext{
${ }^{3}$ Cfr. ROGALL, Klaus, "Beweiserhebungs- und Beweisverwertungsverbote im Spannungsfeld zwischen den Garantien des Rechtsstaates und der effektiven Bekämpfung von Kriminalität und Terrorismus", JZ t. 17 (2008), pp. 818-830, p. 821; ROGALL, Klaus, "Beweisverbote im System des deutschen und des amerikanischen Strafverfahrensrechts”, en: WOLTER, Jürgen; FEIGEN, Hanns W. (Coord.), Zur Theorie und Systematik des Strafprozeßrechts, Neuburg y otros: Hermann Luchterhand Verlag, 1995, pp. 113-160, p. 125.

${ }^{4}$ BELING, Ernst, Die Beweisverbote als Grenzen der Wahrheitserforschung im Strafprozess: Sonderausgabe, 2. Ed., Darmstadt: Buchges, 1968, passim.
} 
Polít. crim. Vol. 13, N 25 (Julio 2018) Art. 4, pp. 144-174.

[http://www.politicacriminal.cl/Vol_13/n_25/Vol13N25A4.pdf]

debate. ${ }^{5}$ Si bien un estudio acabado de las prohibiciones probatorias en el derecho alemán resulta imposible de ser tratado íntegramente en el presente artículo, sus principales alcances y contenido serán analizados resumidamente a continuación.

\subsection{Prohibiciones de obtención y prohibiciones de valoración de prueba en el derecho alemán}

Las prohibiciones probatorias pueden a su vez clasificarse en prohibiciones de producción de prueba ("Beweiserhebungsverbote") y prohibiciones de valoración de prueba ("Beweisverwertungsverbote").

El primero de dichos conceptos comprende aquellas prohibiciones de producir u obtener un determinado medio de prueba, cuando dicha acción resulte procesalmente ilícita. ${ }^{6} \mathrm{Al}$ respecto, podemos constatar la existencia de tres grandes fuentes de prohibiciones de producción de prueba: (1) normas que prohíben expresamente la obtención de un determinado medio de prueba; (2) casos en los cuales los requisitos específicos consagrados por el legislador para autorizar una determinada diligencia investigativa, dirigida a la obtención de material probatorio, no se cumplen; y por último (3) aquellos casos en que una determinada diligencia investigativa no encuentra sustento alguno en la ley. ${ }^{7}$ Dichas hipótesis corresponden, en su mayoría, a vulneraciones de reglas establecidas en la legislación procesal, que prohíben a los órganos persecutores la obtención de prueba ya sea totalmente, o bien sin dar cumplimiento previo a determinados requisitos, restringiendo con ello sus facultades de actuación.

Por su parte, bajo el concepto general de prohibiciones de valoración de prueba se comprenden aquellas proscripciones de incluir determinados medios de prueba como elementos a considerar por el juez en la valoración de la prueba. ${ }^{8}$ De este modo, se entiende a éstas prohibiciones como límites al principio de libre valoración de la prueba consagrado en el § 261 de la Ordenanza Procesal Penal alemana (StPO). ${ }^{9}$

\footnotetext{
${ }^{5}$ La actualidad y relevancia del tema se ve reflejada, por ejemplo, en el hecho de haber sido las prohibiciones probatorias el tema escogido como objeto de discusión en materia penal, en las 67. Jornadas nacionales de derecho, llevadas a cabo el año 2008 en la ciudad de Erfurt, Alemania.

6 Cfr. PITSCH, Christoph, Strafprozessuale Beweisverbote: eine systematische, praxisnahe und rechtsvergleichende Untersuchung unter besonderer Berücksichtigung des Steuerstrafverfahrens, der Zufallsfunde und der Fernwirkungsproblematik, Hamburgo: Kovac, 2009, p. 76; ROGALL, "Beweiserhebungsund Beweisverwertungsverbote", cita nota $\mathrm{n}^{\circ}$ 3, p. 821; ROGALL, Klaus, "Grundsatzfragen der Beweisverbote", en: HÖPFEL, Frank; HUBER, Barbara (Ed.), Beweisverbote in Ländern der EU und vergleichbaren Rechtsordnungen, Exclusion of Evidence Within the EU and Beyond, Europäisches Kolloquium Wien, 18. - 20. September 1997, Freiburg i. Br.: Iuscrim, 1999, pp. 119-148, p. 126; ROGALL, "Beweisverbote im System", cit. nota $\mathrm{n}^{\circ}$ 3, p. 144; ROGALL, Klaus, "Gegenwärtiger Stand und Entwicklungstendenzen der Lehre von den strafprozessualen Beweisverboten”, ZStW t. 91 (1979), pp. 1-44, p. 2.

${ }^{7}$ Cfr. ROGALL, Klaus, "Beweiserhebungs- und Beweisverwertungsverbote", cit. nota n 3, p. 821; ROGALL, "Grundsatzfragen", cit. nota n 6, p. 126; ROGALL, "Beweisverbote im System", cit. nota n 3, p. 144.

${ }^{8}$ Cfr. LÖWE, Ewald, ROSENBERG, Werner, ERB, Volker, ESSER, Robert, FRANKE, Ulrich, GRAALMANNSCHEERER, Kirsten, HILGER, Hans, IGNOR, Alexander, GERBER, Friederike, Die Strafprozeßordnung und das Gerichtsverfassungsgesetz: Großkommentar, Berlin; New York: de Gruyter, 2016, GÖSSEL, Einl. Sección . L. Rdn. 7; JAHN, Matthias, "Beweiserhebungs- und Beweisverwertungsverbote im Spannungsfeld zwischen den Garantien des Rechtsstaates und der effektiven Bekämpfung von Kriminalität und Terrorismus", en: Ständigen Deputation des deutschen Juristentages (Ed.), Verhandlungen des Siebenundsechzigsten Deutschen Juristentages: Erfurt 2008, Band I Gutachten, München: C.H. Beck, 2008, pp. C 1 - C 128, p. C 31; PITSCH, Strafprozessuale Beweisverbote, cit. nota ${ }^{\circ}$ 6, p. 78; ROGALL, "Grundsatzfragen", cit. nota n 6, p. 126; WOHLERS, Wolfgang, "Verwertungs-, Verwendungs- und/oder Belastungsverbote - die Rechtsfolgenseite der Lehre von den Beweisverwertungsverboten", en: HERZOG, SCHLOTHAUER, WOHLERS (Ed.), Rechtsstaatlicher Strafprozess und Bürgerrechte: Gedächtnisschrift für Edda Weßlau, Berlin: Duncker \& Humbot, 2016, pp. 427444, p. 434.

${ }^{9}$ Cfr. LÖWE, Ewald, ROSENBERG, Werner, ERB, Volker, ESSER, Robert, FRANKE, Ulrich, GRAALMANNSCHEERER, Kirsten, HILGER, Hans, IGNOR, Alexander, GERBER, Friederike, Die Strafprozeßordnung, cit.
} 
148 CORREA, Carlos. "Más Más allá de la regla de exclusión: prohibiciones probatorias en el Derecho chileno - con especial referencia al Derecho alemán -".

En contraposición a lo que sucede -por regla general- respecto de las prohibiciones de producción de prueba, las prohibiciones de valoración de prueba se encuentran sólo de manera excepcional y en muy contados casos consagradas de manera expresa en la ley alemana. Ejemplos paradigmáticos a este respecto lo constituyen en primero lugar el $§ 136 \mathrm{a}$ inc. $3^{\circ} \mathrm{StPO}$, que prohíbe al juez valorar aquella declaración del imputado que hubiese sido obtenida mediante alguno de los métodos de interrogatorio prohibidos, indicados en el inciso primero de la referida disposición. ${ }^{10}$ Igualmente, el $\S 69$ inc. $3^{\circ}$ StPO que extiende dicha prohibición a la declaración prestada por testigos.

Las prohibiciones de valoración de prueba pueden, de acuerdo a la doctrina mayoritaria ${ }^{11}$-a partir de las investigaciones efectuadas a este respecto fundamentalmente por Rogall ${ }^{12} \mathrm{y}$ Dencker ${ }^{13}$ a fines de la década de 1970- ser a su vez subdivididas en prohibiciones de valoración dependientes ("unselbständige") e independientes ("selbständige”).

Prohibiciones de valoración de prueba dependientes son aquellas reconocidas como consecuencia (y en ese sentido, efectivamente dependientes) de una vulneración previa a una regla de producción de prueba. Prohibiciones de prueba independientes por el contrario, son aquellas cuyo origen no se remite a la infracción de una regla de producción de prueba. En estos casos, es la valoración misma del medio de prueba la que resulta contraria a alguna de las garantías contenidas en la Ley Fundamental alemana. ${ }^{14}$ A este segundo grupo pertenecen sobre todo aquellas prohibiciones de prueba llamadas constitucionales, así como algunas prohibiciones de valoración establecidas expresamente por el legislador, con independencia de la licitud en la obtención del medio de prueba cuestionado. ${ }^{15}$

La distinción entre prohibiciones de producción y prohibiciones de valoración de prueba resulta fundamental para comprender el tratamiento jurídico que en Alemania se le ha dado a lo que en nuestra doctrina se conoce como prueba ilícita. En este sentido, la principal interrogante que ha sido objeto de incesante discusión doctrinaria y jurisprudencial -sobre todo en los últimos

nota. $\mathrm{n}^{\circ}$ 8, GÖSSEL, Einl. Sección L. Rdn. 7; MEYER-GOßNER, Lutz: SCHMITT, Bertram, Strafprozessordnung: Gerichtsverfassungsgesetz, Nebengesetze und ergänzende Bestimmungen, 58. Ed. München: Beck, 2015, Einl. Rdn. 55; PITSCH, Strafprozessuale Beweisverbote, cit. nota n 6, p. 78; ROGALL, Klaus, "Beweiserhebungs- und Beweisverwertungsverbote", cita nota $n^{\circ} 3$, p. 822; ROGALL, "Gegenwärtiger Stand", cit. nota $n^{\circ} 6$, p. 2.

${ }^{10}$ Abuso, engaño, hipnosis o tormentos.

11 De acuerdo con JÄGER, Christian, "Beweiserhebungs- und Beweisverwertungsverbote als prozessuale Regelungsinstrumente im strafverfolgenden Rechtsstaat. Zugleich ein Beitrag zum 67. Deutschen Juristentag", GA t. 155 (2008), pp. 473-499, p. 474; JAHN, "Beweiserhebungs- und Beweisverwertungsverbote im Spannungsfeld", cit. nota $n^{\circ}$ 8, C 32; REINECKE, Jan, Die Fernwirkung von Beweisverwertungsverboten, München: VVF, 1990, p. 6.

${ }^{12}$ ROGALL, "Gegenwärtiger Stand”, cit. nota n 6, p. 3 y ss.; ROGALL, Klaus, Der Beschuldigte als Beweismittel gegen sich selbst: ein Beitrag zur Geltung des Satzes "Nemo tenetur seipsum prodere" im Strafprozeß, Berlin: Duncker \& Humblot, 1977, pp. 202 y ss.

${ }^{13}$ DENCKER, Friedrich, Verwertungsverbote im Strafprozeß: ein Beitrag zur Lehre von den Beweisverboten, Köln; München y otros: Heymann, 1977, pp. 10 y ss.

${ }^{14}$ Al respecto, vid. GÖSSEL, Karl Heinz, "Verfassungsrechtliche Verwertungsverbote im Strafverfahren”, $J Z$, t. 8 (1984), pp. 361-364, pp. 361 y ss.; STÖRMER, Rainer, "Strafprozessuale Verwertungsverbote in verschiedenen Konstellationen", JURA t. 8 (1994), pp. 621-628, pp. 621 y ss.

${ }^{15}$ Por ejemplo los $\S 252$ y 108 inc. 2 StPO. Cfr. ROGALL, Klaus, "Das Verwendungsverbot des $\S 393$ II AO”, en: HIRSCH, WOLTER, BRAUNS (Ed.), Festschrift für Günther Kohlmann, Köln: OVS Verlag Dr. Otto Schmidt, 2003, pp. 465-498, p. 481; ROGALL, "Beweisverbote im System”, cita nota $n^{\circ} 3$, p. 146, nota al pie $n^{\circ}$ 211; ROGALL, "Gegenwärtiger Stand", cit. nota n 6, p. 3 y s. 
Polít. crim. Vol. 13, N 25 (Julio 2018) Art. 4, pp. 144-174.

[http://www.politicacriminal.cl/Vol_13/n_25/Vol13N25A4.pdf]

50 años ${ }^{16}$ - dice relación con la determinación de los criterios que permiten delimitar aquellos casos en los cuales la infracción a una regla de obtención de prueba traerá como consecuencia una prohibición de valoración de la prueba así obtenida (dependiente). O como Gössel hace más de treinta años certeramente señalara, la pregunta referida a "la determinación de aquellos criterios materiales que permitan diferenciar entre aquellas prohibiciones de producción de prueba irrelevantes, de aquellas cuya infracción acarrea la no valoración del medio de prueba obtenido en contravención a dicha prohibición". ${ }^{17}$

Si bien una respuesta acabada a dicha interrogante resulta imposible de ser agotada en la presente investigación, podemos indicar brevemente las directrices que actualmente consideran la doctrina y la jurisprudencia, para excluir del campo de acción de la libre valoración de la prueba ciertos elementos obtenidos con infracción a reglas de producción probatoria.

Para un sector importante de la doctrina, ${ }^{18}$ la respuesta a la pregunta sobre el criterio de determinación de las prohibiciones de valoración de prueba dependientes debe buscarse en el llamado "fin de protección de la norma" (de producción de prueba) infringida ("Schutzwecklehre"). Así, de acuerdo a esta postura, deberá aceptarse una prohibición de valoración de prueba en aquellos casos en los cuales la ratio legis de la regla de obtención de prueba infringida, importe a su vez una prohibición de valoración de prueba. En palabras de Rudolphi, fiel representante de esta postura, una prohibición de valoración de prueba deberá determinarse

"a partir del sentido y finalidad del precepto lesionado; esto es, cuando el legislador con la incorporación de la norma (de obtención) infringida persiguió como fin, evitar que los medios de prueba producidos con infracción a dicha regla lleguen a formar parte de la convicción del juez contenida en la sentencia". ${ }^{19}$

\footnotetext{
${ }^{16}$ Punto de inflexión en la discusión doctrinaria alemana, corresponde a las 46. Jornadas Jurídicas alemanas, celebradas en 1966 en la ciudad de Essen, y que tuvieron como tema central de la sección "Derecho Penal" el análisis de las llamadas prohibiciones probatorias.

${ }^{17}$ GÖSSEL, Karl Heinz, "Kritische Bemerkungen zum gegenwärtigen Stand der Lehre von der Beweisverboten im Strafverfahren", NJW (1981), pp. 649-657, p. 650.

${ }^{18}$ Cfr. BEULKE, Werner, "Beweiserhebungs- und Beweisverwertungsverbote im Spannungsfeld zwischen den Garantien des Rechtsstaates und der effektiven Bekämpfung von Kriminalität und Terrorismus", JURA t. 8 (2008), pp. 653-666, p. 655. Representantes de la teoría del fin de protección de la norma son, entre otros: BEULKE, "Beweiserhebungs- und Beweisverwertungsverbote" cit. nota $\mathrm{n}^{\circ}$ 18, p. 656; BEULKE, Werner, "Hypothetische Kausalverläufe im Strafverfahren bei rechtswidrigen Vorgehen von Ermittlungsorganen”, ZStW, t. 41 (1991), pp. 657-680, pp. 663 y ss.; FEZER, Gerhard, Strafprozeßrecht, $2^{\text {a }}$ Ed., München: Juristischer Studienkurs, 1995, caso $\mathrm{n}^{\circ}$ 16, Rdn. 29 y ss.; FEZER, Gerhard, Grundfragen der Beweisverwertungsverbote, Heidelberg: C.F. Müller, 1995, pp. 8 y ss., 20 y ss.; GRÜNWALD, Gerald, Das Beweisrecht der Strafprozeßordnung, Baden-Baden: Nomos, 1993, pp. 141 y ss.; GRÜNWALD, Gerald, "Beweisverbote und Verwertungsverbote im Strafverfahren”, $J Z$ t. 15/16 (1966), pp. 489-501, pp. 492 y ss.; JÄGER, Christian, Beweisverwertung und Beweisverwertungsverbote im Strafprozess, München: C.H. Beck, 2003, pp. 131 y ss.; KNAUER, Christoph, KUDLICH, Hans, SCHNEIDER, Hartmut, Münchener Kommentar zur Strafprozessordnung, München: Beck, 2014, KUDLICH, Einl. Rdn. 463; LUBIG, Sebastian, Beweisverwertungsverbote im Kartellverfahrensrecht der Europäischen Gemeinschaft, Baden-Baden: Nomos, 2008, p. 29 y s.; PAULUS, Rainer, "Rechtsdogmatische Bemerkungen zum Urkundenbeweis in der Hauptverhandlung des Strafverfahrens”, JuS t. 28 (1998), pp. 873-879, p. 877; PETRY, Horst, Beweisverbote im Strafprozeß, Saarbrücken: Stoytscheff, 1970, pp. 28 ss., 77 ss.; RUDOLPHI, Hans-Joachim, “Die Revisibilität von Verfahrensmängeln im Strafprozeß”, MDR t. 2 (1970), pp. 93100, pp. 97 y ss.; SCHRÖDER, Svenja, Beweisverwertungsverbote und Hypothese rechtmäßiger Beweiserlangung im Strafprozeß, Berlin: Duncker \& Humblot, 1992, p. 53 y s. Desde un punto de vista centrado en el recurso de revisión, vid., entre otros: BLOMEYER, Jürgen, "Die Revisibilität von Verfahrensfehlern im Strafprozeß”, JR t. 4 (1971), pp. 142-150, pp. 142 y ss.; RUDOLPHI, "Die Revisibilität” cit. nota n 18, p. 97 y ss.; SCHÖNEBORN, Christian, "Die strafprozessuale Beweisverwertungsproblematik aus revisionsrechtlicher Sicht", GA t. 122 (1975), pp. 31-41, pp. 35 y s.

${ }^{19}$ RUDOLPHI, “Die Revisibilität” cit. nota n 18, p. 97.
} 
150 CORREA, Carlos. "Más Más allá de la regla de exclusión: prohibiciones probatorias en el Derecho chileno - con especial referencia al Derecho alemán -".

Hoy en día la doctrina mayoritaria ${ }^{20}$ resuelve la pregunta antes mencionada, no a partir del referido fin de protección de la norma, sino en base al resultado de una "ponderación de intereses" ("Abwägunslehre"), referida al caso concreto, entre dos intereses contrapuestos: por un lado, el interés estatal en una eficiente averiguación de la verdad y por otro, el interés individual de los ciudadanos en el adecuado resguardo de sus derechos. ${ }^{21}$ De este modo, la vulneración a una regla de producción de prueba conducirá a una prohibición de valoración de la misma sólo en aquellos casos en los cuales la mencionada ponderación arroje una preponderancia del interés individual del ciudadano en el resguardo de sus derechos, por sobre el interés público en la persecución penal ${ }^{22}$ (por ejemplo, en caso de una declaración obtenida mediante infracción a lo dispuesto en el $\S 136$ StPO, esto es sin habérsele informado al imputado -entre otros- de su derecho a guardar silencio ${ }^{23}$ ). Cuando por el contrario, en el caso concreto el interés estatal en una eficiente persecución sea considerado preponderante en relación al interés individual antes referido, la infracción a una regla de producción de prueba no conducirá a una prohibición de valoración de la misma (dicha situación tendría lugar, paradigmáticamente, respecto de prueba obtenida en vulneración de normas que no protegen directamente al imputado, como lo serían, por ejemplo, aquellos casos en los cuales un funcionario público declara sin contar con la autorización necesaria para hacerlo, expresamente requerida de conformidad al $§ 54 \mathrm{StPO}^{24}$ ).

La ponderación de intereses como método de determinación de las prohibiciones de valoración de prueba generalmente reconocido ha sido -desde un comienzo- objeto de intensas críticas por parte de un sector importante de la doctrina. ${ }^{25}$ Estas objeciones se dirigen fundamentalmente

${ }^{20}$ De acuerdo con ENGLÄNDER, Armin, VOLK, Klaus, Grundkurs StPO, 8a Ed., München: Beck, 2013, § 28, Rdn. 11; HARTMANN, Arthur, SCHMIDT, Rolf, Strafprozessrecht: Grundzüge des Strafverfahrens, 4a Ed., Grasberg bei Bremen: Schmidt, Dr. Rolf Verlag, 2012, Rdn. 1074; JAHN, "Beweiserhebungs- und Beweisverwertungsverbote im Spannungsfeld”, cit. nota $n^{\circ}$ 8, C 58; KINDHÄUSER, Urs, Strafprozessrecht, 4a Ed., Baden-Baden: Nomos, 2015 § 23, Rdn. 16; PELZ, Christian, Beweisverwertungsverbote und hypothetische Ermittlungsverläufe, Tesis Doctoral, Universidad de München, inédito, 1993, p. 36; SCHRÖDER, Beweisverwertungsverbote, cit. nota $\mathrm{n}^{\circ}$ 18, p. 46. Para otra opinión, vid. DALLMEYER, Jens, Beweisführung im Strengbeweisverfahren, $2^{\mathrm{a}}$ Ed., Norderstedt: Books on demand GmbH, 2008, p. 156; WOHLERS, "VerwertungsVerwendungs", cit. nota ${ }^{\circ} 8$, pp. 427 y s.

${ }^{21}$ Cfr. ALSBERG, Max; NÜSE, Karl-Heinz; DALLMEYER, Jens, Der Beweisantrag im Strafprozess, 6a Ed., Köln: Heymanns, 2016, Rdn. 917; DALAKOURAS, Theoharis, Beweisverbote bezüglich der Achtung der Intimsphäre: unter besonderer Berücksichtigung der Grundrechtsproblematik sowie des griechischen Rechts, Berlin: Duncker \& Humblot, 1988, pp. 112 y ss., pp. 122 y ss.; GROPP, Walter, "Zur Verwertbarkeit eigenmächtig aufgezeichneter (Telefon-) Gespräche - Der Fall Schenk und die Lehre von den Beweisverboten”, StV t. 5/1989 (1989), pp. 216-228, p. 220; KELNHOFER, Evelyn, Hypothetische Ermittlungsverläufe im System der Beweisverbote, Berlin: Duncker \& Humblot, 1994, p. 67; MERGNER, Tobias, Fernwirkung von Beweisverwertungsverboten, Tesis Doctoral, Universidad de Köln, inédita, 2005, p. 55; ROGALL, "Gegenwärtiger Stand", cit. nota n 6, pp. 29 y ss.; WOLTER, Jürgen, "Repressive und präventive Verwertung tagebuchartiger Aufzeichnungen - zugleich Besprechung der Tagebuch-Entscheidung des BVerfG-“" StV t. 29 (1990), pp. 175-180, p. 177; WOLTER, Jürgen, “Anmerkung zum Urteil des BGH vom 24.08.1983 NStZ 1984, 275 ff.", NStZ t. 6 (1984), pp. 276-278, pp. 277 y s.

${ }^{22}$ ROGALL, "Gegenwärtiger Stand", cit. nota n 6, p. 30. Véase además, ROGALL, Klaus, "Hypothetische Ermittlungsverläufe im Strafprozeß”, NStZ t. 9 (1988), pp. 385-393, p. 391; RÖGER, Ralf, Die Verwertbarkeit des Beweismittels nach $\$ 81$ a StPO bei rechtswidriger Beweisgewinnung, Frankfurt a.M.: Lang, 1994, p. 87 y s. ${ }^{23}$ BGHSt 38, 214.

${ }^{24}$ BGH MDR 1951, 275.

${ }^{25}$ Crit. entre otros, BEULKE, "Hypothetische Kausalverläufe", cit. nota n 18, pp. 663 y s.; DALLMEYER, Beweisführung, cit. nota $\mathrm{n}^{\circ}$ 20, p. 157 y ss.; GRÜNWALD, Das Beweisrecht, cit. nota $\mathrm{n}^{\circ} 18$, pp. 155 y ss.; MÜSSIG, Bernd, "Beweisverbote im Legitimationszusammenhang von Strafrechtstheorie und Strafverfahren", GA t. 146 (1999), pp. 119-142, p. 139; STÖRMER, "Strafprozessuale Verwertungsverbote”, cit. nota n 14, pp. 625 y s.; STÖRMER, Rainer, Dogmatische Grundlagen der Verwertungsverbote: eine Untersuchung über die Strukturen strafprozessualer Verwertungsverbote unter dem Einfluss der Verfassung und der Grundsätze des 
Polít. crim. Vol. 13, N 25 (Julio 2018) Art. 4, pp. 144-174.

[http://www.politicacriminal.cl/Vol_13/n_25/Vol13N25A4.pdf]

en contra de la imprevisibilidad en los resultados que dicho método genera, motivada principalmente por la ausencia de reglas claras que permitan prevenir eventuales resultados contradictorios al momento de ponderar. Así, se ha criticado el extremo subjetivismo del que adolecería dicha teoría, y el consiguiente "decisionismo judicial" que ésta conllevaría. ${ }^{26}$ Categórico ha sido a este respecto Amelung, ${ }^{27}$ quien al momento de criticar dicha teoría ha hablado de verdaderas "decisiones adoptadas de acuerdo a la preferencia política de cada juez".

A partir de dichas objeciones, en los últimos años, un sector relevante de la doctrina encabezado por Rogall, ha venido desarrollando una teoría que, prescindiendo de la criticada ponderación abstracta entre dos intereses contrapuestos, permita al juez determinar la valoración o prohibición de valoración de un determinado medio de prueba a partir de metarreglas examinadas en base a un análisis concreto de distintos intereses en juego. ${ }^{28}$ En este sentido, la llamada "Teoría normativa de las consecuencias de un error" ("normative Fehlerfolgenlehre") ha propuesto un sistema para la determinación de prohibiciones de valoración de prueba a partir de la ponderación de tres criterios específicos: la relevancia específica de la infracción de ley procesal en el caso concreto; el significado de la infracción de ley procesal para los intereses individuales legalmente protegidos por la norma vulnerada, y por último, la necesidad de valoración de la prueba en consideración al interés estatal de persecución penal. ${ }^{29}$

A partir del análisis ponderado de dichos criterios, se busca generar constelaciones de casos en las cuales, en primer término, se deberá acoger una prohibición de valoración probatoria. Esto sucederá por ejemplo, en aquellos supuestos en los que la intervención de los funcionarios persecutores ha afectado el núcleo de una garantía fundamental, o bien, cuando la intervención tenga como objetivo buscado, eludir o privar al imputado de sus garantías. Por el contrario, deberá rechazarse una prohibición de valoración, por ejemplo, en todos aquellos casos en los cuales la infracción de ley afecte exclusivamente derechos de terceros, más no del imputado, o bien, cuando la prueba conseguida con infracción de reglas de obtención, constituya un elemento probatorio de descargo para el imputado.

Punto de partida del tratamiento del tema por parte de la jurisprudencia alemana, corresponde al principio sostenido una y otra vez por el Tribunal Supremo alemán, en el sentido de que no toda infracción a reglas de producción de prueba generará como consecuencia necesaria una

öfentlichen Rechts, Marburg: Elwert, 1992, pp. 184 y ss.; WEIGEND, Thomas, "Anmerkung zum Beschluss des LG Frankfurt v. 9.4.2003 - 5/22 Ks 3490 Js 230118/02”, StV t. 8 (2003), pp. 436-440, pp. 439 y s.

${ }^{26}$ Cfr. DALLMEYER, Beweisführung, cit. nota ${ }^{\circ}$ 19, p. 159 y s.; SCHRÖDER, Beweisverwertungsverbote, cit. nota ${ }^{\circ} 18$, p. 46; STÖRMER, Dogmatische Grundlagen, cit. nota ${ }^{\circ}$ 25, p. 191.

27 AMELUNG, Knut, "Subjektive Rechte in der Lehre von den strafprozessualen Beweisverboten”, en: SCHULZ, Joachim, VORMBAUM, Thomas, Festschrift für Günter Bemmann: zum 70. Geburtstag am 15. Dezember 1997, Baden-Baden: Nomos, 1997, pp. 504-523, p. 522; AMELUNG, Knut, “Grundfragen der Verwertungsverbote bei beweissichernden Haussuchungen im Strafverfahren”, NJW (1991), pp. 2533-2540, p. 2533.

${ }^{28}$ Cfr. ROGALL, Klaus, "Beweiserhebungs- und Beweisverwertungsverbote", cita nota n 3, p. 824; ROGALL, Klaus, "Über die Folgen der rechtswidrigen Beschaffung des Zeufenbeweises im Strafprozess", JZ t. 19/1996 (1996), pp. 944-955, p. 954. Detallado al respecto: ROGALL, “Grundsatzfragen”, cit. nota n 6, p. 143 y ss. En este sentido también SCHNEIDER, Hartmut, "Zur Berücksichtigung hypothetischer Ermittlungsverläufe in Fällen grob fehlerhafter Annahme von Gefahr im Verzug bei Wohnungsdurchsuchungen”, NStZ, Sonderheft 2009 (2009), pp. 46-52, pp. 48 y 52. En la jurisprudencia BVerfGE 130, 1 (29 f.).

${ }^{29}$ Cfr. ROGALL, Klaus, "Beweiserhebungs- und Beweisverwertungsverbote", cita nota n 3, p. 824. Detallado al respecto: ROGALL, “Grundsatzfragen”, cit. nota n 6, p. 143 y ss. En este sentido, además SCHNEIDER, "Zur Berücksichtigung”, cit. nota ${ }^{\circ} 28$, pp. 48 y 52. En la jurisprudencia BVerfGE 130, 1 (29 f.). 
152 CORREA, Carlos. "Más Más allá de la regla de exclusión: prohibiciones probatorias en el Derecho chileno - con especial referencia al Derecho alemán -".

prohibición de valoración del elemento de prueba así obtenido. ${ }^{30} \mathrm{Al}$ respecto, tanto la jurisprudencia reciente del Tribunal Supremo alemán ${ }^{31}$ como del Tribunal Constitucional federal alemán, ${ }^{32}$ en concordancia con la doctrina mayoritaria, han sostenido, que la decisión a favor o en contra de la valoración de un determinado medio de prueba debe resolverse en cada caso concreto, a partir de una ponderación de intereses contrapuestos.

Sin embargo hoy en día, y en sintonía con la mencionada "Teoría normativa de las consecuencias de un error", la ponderación que se efectúa caso a caso por parte de la jurisprudencia ha mutado progresivamente desde el mero análisis abstracto de intereses contrapuestos (en el sentido propuesto por la doctrina mayoritaria), hacia una creciente normativización y concretización de la misma. ${ }^{33}$ De este modo, mediante la formulación de reglas dirigidas al juez de la instancia, el Tribunal Supremo ha generado progresivamente un sistema casuístico en pos de predeterminar la valoración o no valoración de un determinado medio de prueba en el caso concreto. Así, por ejemplo, ha reconocido la jurisprudencia alemana más reciente una prohibición de valoración de prueba, en todos los casos en los cuales la prueba hubiese sido obtenida mediante infracción de garantías de carácter grave, arbitraria o consciente, por parte de los órganos persecutores. ${ }^{34}$

\footnotetext{
${ }^{30}$ BGHSt 58, 301 (307); 58, 84 (96); 56, 127 (132); 51, 285 (289 f.); 44, 243 (249); 42, 15 (21); 38,372 (373 f.); 24, 125 (130). BVerfGE 130, 1 (29); 9, 174 (196); BVerfG NStZ 2006, 46 (47); 2000, 488 (489); 2000, 489 (490). BVerfG wisstra 2011, 61 (64); BVerfG NJW 2009, 3225; 2000, 3557.

${ }^{31}$ BGH NStZ-RR 2014, 318 (319) ; BGHSt 58, 301 (307 f.); 58, 84 (96); 56, 127 (132, 135); 52, 110 (116); 51, 285 (290); 47, 172 (179); 44, 243 (249); 42, 170 (172, 174); 42, 139 (157); 42, 15 (21); 38, 372 (373 ff.); 38,214 (219 ff.); 37, 30 (32); 35, 32 (34); 34, 397 (401); 31, 304 (307); 27, 355 (357); 24, 125 (130 ff.); 19, 325 (329); BGH NJW 2003, 2034 (2035); Cfr. DALAKOURAS, Beweisverbote, cit. nota $\mathrm{n}^{\circ}$ 21, p. 125; JAHN, "Beweiserhebungs- und Beweisverwertungsverbote im Spannungsfeld", cit. nota n 8, C 46; ROXIN, Claus, "Die Rechtsprechung des Bundesgerichtshofs zum Strafverfahrensrecht - Ein Rückblick auf 40 Jahre -", en: JAUERNIG, Othmar, ROXIN, Claus, 40 Jahre Bundesgerichtshof: Festveranstaltung am 1. Oktober 1990 mit Ansprache des Präsidenten des Bundesgerichtshofes, Heidelberg: C.F. Müller, 1991, pp. 66-99, p. 70.

${ }^{32}$ BVerfGE 130, 1 (22 ff.).BVerfG NJW 2010, 2937 (2938); 2009, 3225; 2007, 499 (503); BVerfG NStZ 2011, 103.

${ }^{33}$ Cfr. EISENBERG, Ulrich, Beweisrecht der StPO: Spezialkommentar, 9a Ed, München: Beck, 2015, Rdn. 365; HAUF, Claus-Jürgen, "Ist die "Rechtskreistheorie" noch zu halten? Eine neue Konzeption zur Frage von Verfahrensfehlern und Beweisverwertungsverboten", NStZ t. 10 (1993), pp. 457-462, pp. 460 y s.; ROGALL, "Gegenwärtiger Stand", cit. nota n 6, p. 25 y s.

${ }^{34}$ BVerfGE 130, 1 (28); 125, 260 (339 f.); 113, 29 (61); BVerfG NJW 2011, 2783 (2784); 2008, 3053 (3054); 2006, 2684 (2686); 2005, 1917 (1923); BVerfG wistra 2011, 61 (64). También en este sentido BGH NStZ-RR 2014, 318 (319); BGH NStZ 2012, 104 (105). Cfr. LÖWE, Ewald, ROSENBERG, Werner, ERB, Volker, ESSER, Robert, FRANKE, Ulrich, GRAALMANN-SCHEERER, Kirsten, HILGER, Hans, IGNOR, Alexander, GERBER, Friederike, Die Strafprozeßordnung, cit. nota. N 8, GÖSSEL, Einl. Sección L. Rdn. 43.
} 
Polít. crim. Vol. 13, № 25 (Julio 2018) Art. 4, pp. 144-174.

[http://www.politicacriminal.cl/Vol_13/n_25/Vol13N25A4.pdf]

\subsection{La denominada "concepción unitaria" de las prohibiciones de prueba en el Derecho alemán}

En Alemania, tanto la doctrina mayoritaria, ${ }^{35}$ como la jurisprudencia del Tribunal Constitucional Federal ${ }^{36}$ han sostenido que las denominadas "prohibiciones probatorias", rigen indistintamente en todas las etapas del procedimiento.

De acuerdo a esta concepción -llamada unitaria- de las prohibiciones probatorias, un elemento de prueba no susceptible de valoración por parte del tribunal no puede servir como fundamento de una decisión jurisdiccional, ni en la etapa de investigación, ni en el procedimiento intermedio, ni tampoco en la audiencia de juicio.

Como analizaremos posteriormente, dicha concepción unitaria puede servir de base para el reconocimiento de prohibiciones de prueba en el derecho chileno, más allá del ámbito de aplicación de la regla de exclusión del CPP.

\section{La regla de exclusión contenida en el Art. 276 inc. $3^{\circ}$, segunda hipótesis del Código Procesal Penal chileno}

Como se mencionó anteriormente, en un claro contraste con la antigua regulación consagrada en el CdPP, donde (al igual como sucede en Alemania) no existía disposición alguna que regulara de modo general la exclusión, o bien la imposibilidad de valorar un medio de prueba en base su obtención contraria a derecho, el legislador chileno consagró el año 2000 por medio del art. 276 CPP una regla positiva de exclusión de prueba. Precisamente, la segunda de las hipótesis indicadas en el inciso tercero de la referida disposición ordena al juez de garantía la exclusión -en la audiencia de preparación del juicio oral- de aquellas pruebas "que hubieren sido obtenidas con inobservancia de garantías fundamentales".

La aplicación de dicha regla presupone la concurrencia de tres requisitos copulativos: en primer lugar se requerirá de una infracción de norma. Ello sucederá, por regla general en el proceso penal, mediante infracciones cometidas por parte de las policías, o respectivamente del

\footnotetext{
${ }^{35}$ DALLMEYER, Beweisführung, cit. nota n 20, p. 78 y s.; DENCKER, Friedrich, “Über Heimlichkeit, Offenheit und Täuschung bei der Beweisgewinnung im Strafverfahren - Anmerkungen aus Anlaß zweier Entscheidungen des BGH", StV t. 5 (1994), pp. 667-683, p. 670; DENCKER, Verwertungsverbote im Strafproze 3 , cit. nota ${ }^{\circ} 13$, pp. 53 y 75; EISENBERG, Beweisrecht der StPO, cit. nota ${ }^{\circ}$ 33, Rdn. 334, 356 y 635; HENGSTENBERG, Achim, Die Frühwirkung der Verwertungsverbote: eine Untersuchung der Bedeutung der Beweisverwertungsverbote für die strafprozessualen Verdachtsbeurteilungen, Hamburg: Kovac, 2007, pp. 30 y s.; KNAUER, Christoph, KUDLICH, Hans, SCHNEIDER, Hartmut, Münchener Kommentar, cit. nota $\mathrm{n}^{\circ} 18$, KUDLICH, Einl. Rdn. 449; KNAUTH, Alfons, "Beweisrechtliche Probleme bei der Verwertung von Abhörmaterial im Strafverfahren" NJW (1978), pp. 741-745, pp. 742 y s.; MAUL, Heinrich, ESCHELBACH, Ralf, "Zur "Widerspruchslösung" von Beweisverbotsproblemen in der Rechtsprechung”, StraFo Mayo/Junio 1996 (1966), pp. 66-70, p. 69; PITSCH, Strafprozessuale Beweisverbote, cit. nota n 6, p. 83; ROGALL, Klaus, "Grund und Grenzen der "qualifizierten" Belehrung im Strafprozess", en: GEISLER, KRAATZ, KRETSCHMER, SCHNEIDER, SOWADA (Ed.), Festschrift für Klaus Geppert zum 70. Geburtstag am 10. März 2011, Berlin y otros: de Gruyter, 2011, pp. 519-547, p. 536; ROGALL, "Grundsatzfragen", cit. nota n 6, p. 130; ROGALL, "Gegenwärtiger Stand", cit. nota $\mathrm{n}^{\circ}$ 6, p. 7 y s.; SCHLOTHAUER, Reinhold, "Zur Bedeutung der Beweisverwertungsverbote im Ermittlungs- und Zwischenverfahren", en: PRITTWITZ, BAURMANN, GÜNTHER, KUHLEN, MERKEL, NESTLER, SCHULZ, (Ed.), Festschrift für Klaus Lüderssen: zum 70. Geburtstag am 2. Mai 2002, Baden-Baden: Nomos, 2002, pp. 761-772, pp. 761 y ss.; STÖRMER, "Strafprozessuale Verwertungsverbote", cit. nota n 14, p. 625; STÖRMER, Dogmatische Grundlagen, cit. nota $\mathrm{n}^{\circ}$ 25, pp. 241 y 394. En relación al $\S 136$ a StPO: OSMER, Jan-Dierk, Der Umfang des Beweisverwertungsverbotes $\S 136$ a StPO, Tesis Doctoral, Universidad Hamburg, inédita, 1966, p. 56 y s.

${ }^{36}$ Ver a este respecto BVerfGE 44, 353 (383, f.); 34, 238 (238, ff.); OLG Frankfurt, NStZ 1988, 425; JAHN, Matthias, "Grundfragen und aktuelle Probleme der Beweisverwertung im Straf- und Steuerstrafverfahren", en: JAHN, KUDLICH, STRENG (Ed.), Strafrechtspraxis und Reform - Festschrift für Heinz Stöckel zum 70. Geburtstag, Berlin: Duncker \& Humblot, 2010, pp. 259-286, p. 282.
} 
154 CORREA, Carlos. "Más Más allá de la regla de exclusión: prohibiciones probatorias en el Derecho chileno - con especial referencia al Derecho alemán -".

ministerio público, en la etapa de investigación. En segundo término, se requiere que dicha infracción se encuentre causalmente vinculada con la obtención de un medio de prueba que se pretende hacer valer en el juicio oral. Por último, deberá analizarse el contenido de la norma lesionada por medio del acto de obtención de prueba: ${ }^{37}$ así, por mandato del legislador, la regla de exclusión no sanciona cualquier vulneración de normas procesales, sino que por el contrario, sólo tendrá aplicación en aquellos casos en los cuales en la obtención de prueba se hubiesen vulnerado reglas que protegen garantías fundamentales. ${ }^{38}$

Bajo el concepto "garantías fundamentales" en el sentido del art. 276 inc. $3^{\circ} \mathrm{CPP}$ entendemos -siguiendo a la doctrina mayoritaria ${ }^{39}$ - todos aquellos derechos y garantías contenidos en la Constitución Política y -de acuerdo con el art. 5 inc. $2^{\circ}$ de la Carta fundamental- en Tratados Internacionales de Derechos Humanos suscritos y ratificados por nuestro país, susceptibles de ser lesionados por los órganos persecutores al momento de obtener material probatorio. Para la determinación de aquellos derechos encasillados bajo la categoría "garantías fundamentales" resulta especialmente relevante analizar el catálogo contenido en el art. 19 de la Constitución, así como aquel contenido en el art. $14 \mathrm{del}$ "Pacto internacional de derechos civiles y políticos" $" 40$ y art. $8^{\circ}$ de la "Convención americana sobre derechos humanos" - Pacto San José de Costa Rica $^{41}$-.

Las consecuencias procesales que conlleva la concurrencia de alguna de las hipótesis de exclusión de prueba reguladas en el art. 276 del CPP resultan en todos los casos idénticas: concurriendo sus requisitos de procedencia, deberá el juez de garantía, en la audiencia de preparación del juicio oral, excluir dichos elementos de prueba del auto de apertura del juicio oral (Art. 277 e) CPP), impidiéndose con ello que dicha prueba sea finalmente incorporada a la audiencia de juicio.

El art. 276 CPP actúa como una regla de admisibilidad probatoria, cuya función es regular la inclusión de prueba en etapas posteriores del procedimiento. Como ha sostenido la Corte Suprema, ${ }^{42}$ si el juez de tribunal oral admite la incorporación en el juicio de una prueba expresamente excluida por el juez de garantía en la audiencia de preparación y la valora en su sentencia, no sólo excederá el ámbito de su competencia, sino que además lesionará la garantía de un debido proceso.

\subsection{El carácter ineludible de la exclusión de prueba}

De acuerdo al artículo 276 inc. $3^{\circ} \mathrm{CPP}$, el juez "excluirá" las pruebas que hubieren sido obtenidas con inobservancia de garantías fundamentales. De este modo, el tenor literal de dicha

\footnotetext{
${ }^{37}$ Cfr. CAROCCA PÉREZ, Alex, "Una primera aproximación al tema de la prueba ilícita en Chile”, Ius et Praxis, vol. 4 n 2 (1998), pp. 301-322, p. 306; HERNANDEZ BASUALTO, Exclusión, cit. nota n 1, p. 51 y s.

${ }^{38}$ En este sentido, además NUÑEZ OJEDA, Raúl; CORREA ZACARIAS, Claudio, "La prueba ilícita en las diligencias limitativas de derechos fundamentales en el proceso penal chileno", Ius et Praxis, vol. 23 n 1, 2017 , pp. $195-246$, p. 213 y s.

${ }^{39}$ En este sentido: ECHEVERRIA DONOSO, Isabel, Los derechos fundamentales y la prueba ilícita: con especial referencia a la prueba ilícita aportada por el querellante particular y por la defensa, Santiago: Eds. Jurídicas de Santiago, 2010, p. 65; HERNANDEZ BASUALTO, Exclusión, cit. nota n 1, p. 52; HORVITZ LENNON, LOPEZ MASLE, Derecho procesal penal, cit. nota ${ }^{\circ} 1$, p. 188; NUÑEZ OJEDA, CORREA ZACARIAS, "La prueba ilícita", cit. nota n ${ }^{\circ}$ 38, p. 214; ZAPATA GARCÍA, Francisca, La prueba ilícita, Santiago: Lexis Nexis, 2004, pp. 39 y s. Vid. arts. 10, 160 y 373 a) CPP, que se encuentran en directa relación con garantías reconocidas a nivel supralegal.

${ }^{40}$ Firmado el 16 de diciembre de 1966 y ratificado el 10 de febrero de 1972.

${ }^{41}$ Firmado el 22 de septiembre de 1969 y ratificado el 21 de agosto de 1990.

${ }^{42}$ Corte Suprema, Ingreso Rol Nr. 1618-10 (Cons. 14º).
} 
Polít. crim. Vol. 13, № 25 (Julio 2018) Art. 4, pp. 144-174.

[http://www.politicacriminal.cl/Vol_13/n_25/Vol13N25A4.pdf]

disposición es claro en señalar que la exclusión por parte del juez de garantía de aquellas pruebas que hubieren sido obtenidas con inobservancia de garantías fundamentales constituye un deber irrenunciable para éste, que puede incluso ser ejercido de oficio, a falta de solicitud de parte de la defensa.

Igualmente, de acuerdo al derecho vigente no resulta posible admitir excepciones a la aplicación estricta de la regla en caso que concurran sus presupuestos de aplicación, atendiendo a consideraciones externas a ella. Una relativización de la aplicación de la regla por vía jurisprudencial - paradigmáticamente a partir de la ponderación en el caso concreto de intereses contrapuestos- resulta inadmisible en el derecho chileno: ello contraviene el tenor expreso del art. $276 \mathrm{CPP} .{ }^{43}$ En efecto, en caso de tolerar excepciones a la aplicación de la regla, fundadas por ejemplo- en la presencia concreta de un interés público superior al interés particular en el resguardo de garantías del imputado, se pondría en entredicho la vigencia de la regla de exclusión y finalmente de la garantía constitucional por ella protegida. ${ }^{44}$

\subsection{Oportunidad procesal en la cual procede aplicar la regla de exclusión}

El artículo 276 se encuentra contenido dentro del Párrafo $3^{\circ}$, Título II del Libro I CPP, relativo a la audiencia de preparación del juicio oral. Precisamente, durante la referida audiencia deberá el juez de garantía excluir - entre otros - aquellos elementos de prueba en cuya obtención se hubiesen vulnerado garantías fundamentales.

A este respecto cabe preguntarse si fuera de dicha audiencia, esto es antes o después de la misma, resulta posible excluir prueba, o bien desestimarla como elemento susceptible de valoración judicial tendiente a formar convicción en el tribunal al momento de adoptar una decisión. En los acápites $3^{\circ}$ y ss., se analizará el tratamiento de la prueba obtenida con infracción de garantías fundamentales en la etapa de investigación y posteriormente, en los apartados $4^{\circ}$ y ss., en el juicio oral.

\section{Tratamiento de la prueba obtenida con infracción de garantías fundamentales en la etapa de investigación}

A diferencia de lo que sucede en la audiencia de preparación del juicio oral, el CPP no consagra disposición alguna que reconozca la posibilidad de excluir o no valorar elementos de prueba en la etapa de investigación en virtud de su obtención contraria a derecho.

A falta de regla expresa, cabe preguntarse cómo debiese actuar el juez de garantía al momento de resolver -durante la etapa de investigación- solicitudes planteadas por el ministerio público sustentadas en elementos de prueba obtenidos con infracción de garantías fundamentales. Paradigmáticamente nos referimos con ello a peticiones del órgano persecutor referidas a la aplicación de una medida cautelar personal, o bien dirigidas a obtener autorización judicial para efectuar una determinada diligencia investigativa.

\footnotetext{
${ }^{43}$ En el mismo sentido, ECHEVERRIA DONOSO, Los derechos fundamentales, cit. nota n ${ }^{\circ} 39$, pp. 40 y ss. En contra: NUÑEZ OJEDA, CORREA ZACARIAS, "La prueba ilícita”, cit. nota n 38, p. 221 y DIAZ GARCIA, "Derechos Fundamentales", cit. nota ${ }^{\circ} 2$, pp. 156, quienes en base a criterios de proporcionalidad y ponderación de intereses más bien abstractos (y de dudoso contenido específico), relativizan la aplicación de la regla de exclusión. Al respecto, vid. en el derecho alemán, las insistentes críticas contra la ponderación de intereses como criterio suficiente para determinar el contenido de la regla de exclusión esbozadas por los autores indicados en la nota al pie Nr. 25 y que han llevado al progresivo descrédito de dicha teoría en Alemania, como criterio de determinación del contenido material de las prohibiciones de prueba.

${ }^{44}$ El rechazo a la aplicación de criterios de proporcionalidad como fundamento de excepciones a la aplicación de la regla de exclusión ha sido igualmente reconocido por la Corte Suprema en sentencia Nr. 11.482-13 (Cons. $\left.6^{\circ}\right)$.
} 
156 CORREA, Carlos. "Más Más allá de la regla de exclusión: prohibiciones probatorias en el Derecho chileno - con especial referencia al Derecho alemán -".

El juez de garantía puede actuar en estos casos de tres formas distintas:

En primer lugar se podría argumentar que el juez tendría un deber de excluir, en cualquier oportunidad del procedimiento, aquellos medios de prueba obtenidos en infracción de garantías fundamentales. Dicha obligación trascendería la etapa procesal planteada expresamente por el legislador al respecto - preparación del juicio oral - aplicándose la regla contenida en el art. 276 inc. $3^{\circ}$ de manera análoga, respecto de hipótesis similares, pero no reguladas expresamente por el legislador.

Dicha solución resulta inadmisible. En caso de aceptar dicha posibilidad, se privaría de contenido -sin contar con norma expresa- a la etapa intermedia como instancia única de discusión sobre admisibilidad de prueba, dando pie a la formulación de numerosas incidencias en etapas previas del procedimiento.

El legislador ha limitado expresamente las posibilidades de excluir prueba obtenida con infracción de garantías a la etapa de preparación de juicio oral (art. 276 CPP), sin conferir al juez de garantía dicha potestad durante la etapa de investigación. A falta de norma expresa, el juez se encuentra imposibilitado de excluir prueba en etapas previas del procedimiento, con efecto respecto de etapas posteriores del mismo.

A contrario sensu, desde un punto de vista estrictamente formal, podríamos sostener en segundo lugar que el juez de garantía, al no encontrarse sujeto -como se mencionó supra- a regla alguna que le autorice a excluir prueba en la etapa de investigación, se encontraría siempre obligado a valorar en sus decisiones positivamente todos los elementos de prueba disponibles al momento de fundamentar su resolución, sin consideración alguna a su origen. Dicho argumento, sería además compatible con una concepción ilimitada del principio de libre valoración de la prueba ${ }^{45}$ - consagrado en el art. 297 CPP -, que no reconoce límite alguno para el juez al momento de apreciar la prueba.

La mencionada interpretación debe ser igualmente descartada. Pese a que -como se señaló- la aplicación del art. 276 CPP limita la exclusión de prueba exclusivamente a la audiencia de preparación del juicio oral, de ello no se desprende que la prueba obtenida con infracción de garantías fundamentales, deba necesariamente ser valorada positivamente por el juez al momento de adoptar una decisión durante la etapa de investigación.

En este sentido, y como se expondrá pormenorizadamente en los acápites siguientes, el presente trabajo defiende una tercera postura: la existencia residual de prohibiciones de valoración de prueba dependientes en el derecho procesal penal chileno, equivalentes a aquellas reconocidas y desarrolladas por la doctrina y jurisprudencia alemana, aplicables, entre otros, a la etapa de investigación.

Dicha solución, permite superar los problemas que genera la imposibilidad técnica de excluir prueba obtenida mediante vulneración de garantías en la etapa de investigación, permitiendo al juez de garantía resolver las solicitudes planteadas en la referida etapa, sin tener que hacerlo necesariamente en base a prueba ilícitamente obtenida.

La conclusión aquí defendida parte de dos fundamentos, los cuáles serán en seguida analizados.

\footnotetext{
${ }^{45}$ Dicha concepción, era por ejemplo, la seguida por la antigua jurisprudencia del Tribunal Supremo Imperial
} alemán, vid. RGSt 55, 20; RG HRR 1939, 729. En este sentido también BGHSt 2, 351 (353 s.). 
Polít. crim. Vol. 13, № 25 (Julio 2018) Art. 4, pp. 144-174.

[http://www.politicacriminal.cl/Vol_13/n_25/Vol13N25A4.pdf]

\subsection{La función perseguida por la regla de exclusión de prueba}

En primer lugar, resulta necesario impedir al juez valorar en la etapa de investigación prueba obtenida con infracción de garantías a efectos de asegurar la función perseguida por la regla de exclusión consagrada en el CPP.

En efecto, de acuerdo con la posición aquí defendida, la regla tantas veces mencionada, consagrada en el art. 276 inc. $3^{\circ}$ segunda hipótesis CPP tiene por finalidad asegurar la vigencia de las garantías del imputado ante ataques antijurídicos cometidos por los órganos de persecución generados con ocasión de la obtención de prueba. ${ }^{46}$

Por ello, de acuerdo al art. 14 a) del Código Orgánico de Tribunales, es un deber del juez de garantía asegurar los derechos del imputado en el proceso penal. Dicha obligación se vulneraría en caso de aceptar que una infracción a garantías fundamentales quedase sin una efectiva sanción procesal, sirviendo la prueba así obtenida por parte de los órganos persecutores, además, como sustento material de resoluciones judiciales.

En caso de permitir una valoración probatoria a todo evento, las garantías del imputado en el proceso penal se verían doblemente vulneradas. Primero, al momento en el cual el funcionario encargado de recolectar material probatorio accede a éste en contravención de garantías. En segundo término, al momento en que el juez valora positivamente dichos elementos, a efectos de fundamentar una determinada resolución judicial.

\subsection{La coherencia interna del ordenamiento jurídico}

Por otra parte, permitir la valoración a todo evento de un determinado elemento probatorio en la etapa de investigación, aceptando que éste posteriormente podrá ser excluido en la etapa

\footnotetext{
${ }^{46}$ En este sentido, además: DIAZ GARCIA, "Derechos Fundamentales“, cit. nota n 2, pp. 38 y s.; ZAPATA GARCÍA, La prueba ilícita, cit. nota ${ }^{\circ}$ 39, pp. 23 y ss.; ECHEVERRIA DONOSO, Los derechos fundamentales, cit. nota $\mathrm{n}^{\circ} 39$, p. 27. Atribuir fines meramente disuasivos a la regla de exclusión, dirigidos a la policía, en el sentido expresado por la jurisprudencia norteamericana, resulta improcedente en nuestro sistema: la exclusión de prueba no resulta un medio idóneo para lograr un disciplinamiento de los órganos de persecución por cuanto esta sanción procesal, carece de efectos que actúen directamente sobre el funcionario infractor, como sí lo serían por ejemplo, la aplicación de sanciones administrativas o penales. En este sentido, en el derecho alemán: AMELUNG, Knut, Informationsbeherrschungsrechte im Strafprozess, Berlin: Duncker \& Humblot, 1990, p. 18; JÄGER, Beweisverwertung und Beweisverwertungsverbote im Strafprozess, cit. nota $\mathrm{n}^{\circ} 18$, p. 70; KELNHOFER, Hypothetische, cit. nota ${ }^{\circ}$ 21, p. 60; OSSENBERG, Sarah, Die Fernwirkung im deutsch-U.S.- amerikanischen Vergleich: unter bedonderer Berücksichtigung der Funktionen der Beweisverwertungsverbote, Hamburg: Kovac, 2011, p. 30; PELZ, Beweisverwertungsverbote, cit. nota n² 20, pp. 128 y s.; RANFT, Otfried, "Bemerkungen zu den Beweisverboten im Strafprozeß”, en: SEEBODE, Manfred, Festchrift für Günter Spendel zum 70. Geburtstag a, 11. Juli 1992, Berlin y otros: De Gruyter, 1992, pp. 719-736, p. 725; RANSIEK, Andreas, "Rechtswidrige Ermittlungen und die Fernwirkung von Beweisverwertungsverboten", en: FAHL, MÜLLER, SATZGER, SWODOBA, Festschrift für Werner Beulke zum 70. Geburtstag, Heidelberg: Müller, 2015, pp. 949-961, p. 950; ROGALL, "Grundsatzfragen", cit. nota n 6, p. 131; ROGALL, "Beweisverbote im System", cita nota n' 3, p. 149; ROGALL, "Gegenwärtiger Stand", cit. nota n 6, p. 15; STÖRMER, Dogmatische Grundlagen, cit. nota $\mathrm{n}^{\circ}$ 25, p. 199. Jahn (JAHN, "Beweiserhebungs- und Beweisverwertungsverbote im Spannungsfeld", cit. nota $\mathrm{n}^{\circ} 8, \mathrm{C}$ 58) plantea a este respecto promover la disciplina de los órganos persecutorios en el ejercicio de sus funciones a través de un fortalecimiento del derecho penal disciplinario, sobre todo mediante un endurecimiento de las sanciones asociadas a los delitos funcionarios contemplados en el Código Penal. Un análisis pormenorizado de las distintas posiciones sostenidas por la doctrina chilena y alemana para justificar la exclusión o respectivamente la prohibición de valoración de prueba excede del contenido de este trabajo y será analizado en otra oportunidad.
} 
158 CORREA, Carlos. "Más Más allá de la regla de exclusión: prohibiciones probatorias en el Derecho chileno - con especial referencia al Derecho alemán -".

intermedia, daría pie - como acertadamente sostiene López ${ }^{47}$ - a una incoherencia interna del sistema.

En efecto, resultaría contradictorio aceptar por un lado la exclusión de elementos de prueba en la audiencia de preparación del juicio oral (impidiendo así cualquier contacto de parte del tribunal de juicio oral con la prueba excluida), y por otro lado, permitir que idénticos medios de prueba puedan servir de sustento de una resolución judicial, esta vez en la etapa de investigación.

Para ejemplificar lo dicho, consideremos el siguiente caso hipotético: en la audiencia de preparación del juicio oral, el juez de garantía excluye del auto de apertura -atendida su obtención con inobservancia de garantías fundamentales- el principal medio de prueba que incriminaba al imputado: el arma homicida en la que se encontró ADN inculpatorio. En la audiencia de juicio oral, la defensa solicita la revocación de la prisión preventiva en la que se encuentra el imputado atendida la falta de antecedentes que permitan tener por acreditado la participación del acusado en el hecho, requisito de procedencia de dicha medida cautelar contemplado en la letra b) del art. 140 CPP. ¿Puede acaso el juez de tribunal de juicio oral valorar al momento de resolver dicha solicitud incidental, el arma homicida previamente excluida? Desde luego que no. Ahora, ¿debe sin embargo el juez de garantía valorar a todo evento el arma homicida obtenida con infracción de garantías, al momento de resolver la mantención de la prisión preventiva cuando esta se discuta en la etapa de investigación, a sabiendas de su origen espurio? Creemos igualmente que no. Aceptando dicha posibilidad se generaría la antes referida doble vulneración de garantías, fundamentándose la resolución cuestionada en base a una infracción de garantías.

Rechazada por un lado la posibilidad del juez de garantía en orden a excluir prueba durante la etapa de investigación y por otro lado, de valorar positivamente y en todos los casos, los elementos de prueba que sustentan las solicitudes, independiente de su origen, podemos concluir preliminarmente que la solución al problema anteriormente planteado se encuentra en la prohibición de valoración por parte del juez de garantía en la etapa de investigación de los elementos de prueba cuestionados.

En estos casos, nos encontramos frente a verdaderas prohibiciones de prueba dependientes, en el sentido referido por la doctrina alemana: prohibiciones de valoración de prueba generadas como consecuencia de una vulneración previa a una regla de producción de prueba.

El efecto de estas prohibiciones de prueba es desde luego distinto del efecto que genera la exclusión de prueba en virtud de lo establecido en el art. 276 CPP: la prohibición de valoración de la prueba surtirá efecto exclusivamente en la etapa de investigación, y más aún, sólo respecto de la resolución específica en la cual se reconoce, sin tener efecto alguno respecto de decisiones que posteriormente se adoptarán en la etapa de investigación, y sobre todo, sin incidir en lo que finalmente se resuelva en la audiencia de preparación en relación a las eventuales solicitudes de exclusión de prueba planteadas por los intervinientes.

Así, la resolución que adopte el juez de garantía al pronunciarse sobre la prohibición de valoración de un elemento de prueba no generará efecto de cosa juzgada respecto de las

\footnotetext{
${ }^{47}$ HORVITZ LENNON, LOPEZ MASLE, Derecho procesal penal, cit. nota $\mathrm{n}^{\circ} 1$, pp. 205 y s.
} 
Polít. crim. Vol. 13, № 25 (Julio 2018) Art. 4, pp. 144-174.

[http://www.politicacriminal.cl/Vol_13/n_25/Vol13N25A4.pdf]

decisiones de exclusión que se adopten en otra oportunidad procesal, e incluso respecto de nuevas solicitudes formuladas igualmente durante la etapa de investigación. ${ }^{48}$

Dicho lo anterior, resta determinar el criterio de determinación material de dichas prohibiciones, aplicable al sistema chileno. La respuesta a dicha interrogante será analizada posteriormente en el acápite 5.2 del presente trabajo.

En las líneas que siguen, nos centraremos en la etapa de juicio oral, específicamente en el tratamiento que debe recibir por parte del Tribunal de Juicio Oral, aquella prueba obtenida con vulneración de garantías, erróneamente incluida en el auto de apertura o cuya ilicitud resulta desconocida hasta entonces.

\section{La exclusión de prueba en el juicio oral}

El tratamiento de la exclusión de prueba en la etapa de juicio oral se encuentra en un punto intermedio entre la regulación consagrada respecto de la etapa de preparación del juicio oral (punto donde la exclusión de prueba encuentra su máxima expresión en el ordenamiento procesal penal chileno), y la etapa de investigación, donde (como se expuso supra) el legislador no ha consagrado regla alguna que permita al juez excluir prueba.

En efecto, el tratamiento otorgado por el legislador a la exclusión de prueba en la audiencia de juicio oral puede catalogarse de fragmentario, reduciendo su procedencia a tres hipótesis específicas, casos en los cuales la regla de exclusión general de prueba contemplada en el art. 276 CPP no resulta directamente aplicable.

El primer caso excepcional de exclusión probatoria en la etapa de juicio oral, corresponde al art. 334 CPP.

Dicha disposición consagra -en primer término- una prohibición general de incorporar como medios de prueba y de dar lectura durante el juicio oral, registros y documentos que dieren cuenta de actuaciones o diligencias realizadas por la policía o el Ministerio Público. La prohibición contenida en dicha regla, surtirá efecto principalmente en la audiencia de preparación del juicio oral, impidiendo la incorporación en el auto de apertura de los antecedentes allí indicados.

Como excepción a dicha regla, reconoce a continuación el inciso primero de la citada disposición -remitiéndose a los arts. 331 y 332 CPP-, la posibilidad extraordinaria de incorporar al juicio oral o dar lectura en el mismo a registros y documentos, cuando se trate de declaraciones prestadas previamente por un testigo o perito fallecido, incapacitado o incapaz; cuando exista acuerdo de las partes en este sentido; ${ }^{49}$ cuando la no comparecencia fuera imputable al acusado o bien, cuando se trate de declaraciones prestadas por imputados rebeldes. Adicionalmente, el legislador ha permitido incorporar como medio de prueba las declaraciones anteriores del acusado o testigo como apoyo de memoria, para superar contradicciones o bien para solicitar aclaraciones.

\footnotetext{
${ }^{48}$ Esta idea se ve reforzada a la luz del tenor actual del inciso final del art. $132 \mathrm{CPP}$, el cual dispone en su parte final, que la declaración de ilegalidad de la detención no producirá efecto de cosa juzgada en relación con las solicitudes de exclusión de prueba que se efectúen de conformidad a lo previsto en el art. 276 CPP.

${ }^{49}$ Para poder ser válidamente incorporadas, dichas declaraciones deben haber sido recibidas por el juez de garantía en una audiencia especial llevada a cabo de acuerdo a lo dispuesto en los arts. 191, 192 y 280 CPP.
} 
160 CORREA, Carlos. "Más Más allá de la regla de exclusión: prohibiciones probatorias en el Derecho chileno - con especial referencia al Derecho alemán -".

En todo caso, el art. 334 inc. $2^{\circ} \mathrm{CPP}$ consagra una prohibición específica de dar lectura a dichos registros y documentos, aún en aquellos casos en los cuales su lectura se encuentra excepcionalmente admitida -casos ya mencionados-, cuando las actas o documentos, dieren cuenta de actuaciones o diligencias declaradas nulas o en cuya obtención se hubieren vulnerado garantías fundamentales.

Dicha regla permite en consecuencia -excepcionalmente- al tribunal de juicio oral controlar la admisibilidad de registros y documentos en juicio, utilizando como fundamento de una eventual exclusión, los mismos criterios materiales contemplados en el art. 276 inc. $3^{\circ} \mathrm{CPP}$ que sustentan la exclusión general de prueba en la audiencia de preparación del juicio oral.

La segunda posibilidad resulta más compleja de analizar. El art. 336 CPP, que regula la llamada "prueba no solicitada oportunamente", autoriza excepcionalmente al juez de tribunal oral a admitir la recepción de prueba, cuando la parte que desea hacerse valer de ésta, justificare no haber sabido de su existencia sino hasta ese momento.

En dicha oportunidad, entendemos que el juez de tribunal oral al momento de decidir sobre la admisión de prueba no solicitada oportunamente, puede rechazar su inclusión cuando concurrieren alguna de las causales de exclusión contempladas en el art. 276 CPP. Lo anterior resulta posible, por cuanto la incorporación o exclusión de dicha prueba para la etapa de juicio - por desconocimiento de las partes- no fue, ni pudo ser, examinada previamente por el juez de garantía. En este caso, a falta de regla expresa que regule tal situación, deberá el juez de tribunal oral aplicar el art. 276 CPP de manera análoga, tanto en lo referido a los criterios que permiten sustentar la exclusión, como en las consecuencias que esto acarrea.

El examen de inclusión o exclusión por parte del tribunal oral de prueba no solicitada oportunamente, resulta insoslayable. Con ello se busca resguardar efectivamente las garantías del imputado, impidiendo que prueba no controlada previamente en cuya obtención fueron vulnerados derechos, pueda servir de sustento a una eventual sentencia condenatoria.

Ahora bien, aceptada que sea la posibilidad excepcional por parte del tribunal de juicio oral de excluir prueba no solicitada oportunamente, ello no impedirá una eventual contaminación del juez con prueba ilícitamente obtenida. En efecto, el problema central que genera un sistema de exclusión concentrado, basado en una ausencia de diferenciación entre el tribunal que decide sobre la exclusión de prueba (o bien la imposibilidad de valorar la misma) y el que debe dictar sentencia -como sucede de manera marginal en Chile, y como es la regla general en Alemania ${ }^{50}$ radica, a diferencia de lo que sucede en un sistema diferenciado, en la imposibilidad de impedir al juez tomar contacto con la prueba excluida. ${ }^{51}$ Nada impedirá que en estos casos, al menos a un nivel inconsciente, el juez fundamente su decisión en material probatorio ilícitamente obtenido. $^{52}$

El carácter residual y casuístico de la regulación sobre exclusión de prueba en el juicio oral antes referida, nos permite concluir que el legislador decidió limitar la posibilidad de excluir prueba en esta etapa del procedimiento a situaciones excepcionales, en las cuales la exclusión o respectivamente la admisibilidad de elementos probatorios no fue ni pudo ser resuelta por el

\footnotetext{
${ }^{50}$ Vid. WOHLERS, "Verwertungs-, Verwendungs", cit. nota ${ }^{\circ} 8, \mathrm{pp} .432$ y ss.

${ }^{51}$ Cfr. HORVITZ LENNON, LOPEZ MASLE, Derecho procesal penal, cit. nota ${ }^{\circ}$ 1, p. 193.

${ }^{52}$ Cfr. MATURANA MIQUEL, Cristián, MONTERO LÓPEZ, Raúl, Derecho Procesal Penal Tomo II, Santiago: Legal Publishing Chile, 2012, p. 950.
} 
Polít. crim. Vol. 13, № 25 (Julio 2018) Art. 4, pp. 144-174.

[http://www.politicacriminal.cl/Vol_13/n_25/Vol13N25A4.pdf]

juez de garantía en la audiencia de preparación del juicio oral: allí radica precisamente la razón de ser de esta posibilidad excepcional.

\section{1. ¿Exclusión de prueba erróneamente incorporada al auto de apertura del juicio oral?}

Ahora bien, la regulación de hipótesis excepcionales de exclusión de prueba en el juicio oral, no soluciona el problema referido al tratamiento de aquellos elementos probatorios erróneamente admitidos por el juez de garantía en el auto de apertura del juicio oral, pese a adolecer de alguna de las causales de exclusión probatoria contempladas en el art. 276 CPP. ${ }^{53}$

Al respecto se podría argumentar, en primer término, que en dichas situaciones el tribunal de juicio oral se encontraría excepcionalmente facultado para excluir aquella prueba erróneamente admitida. Permitiendo dicha exclusión tardía, en el juicio oral, no sólo se corregiría una resolución erróneamente pronunciada por el juez de garantía, sino que además se daría finalmente un efectivo resguardo a las garantías fundamentales vulneradas.

Dicha argumentación resulta incorrecta. La audiencia de preparación del juicio oral corresponde (salvo las excepciones ya analizadas) a la única oportunidad procesal para discutir la exclusión o admisión de un determinado elemento de prueba en etapas posteriores del procedimiento. Como ha sostenido reiteradamente la Corte Suprema, ${ }^{54}$ la prueba erróneamente aceptada en la audiencia de preparación del juicio oral no puede ser excluida, ni de oficio, ni a solicitud de partes, por el tribunal de juicio oral en lo penal.

En caso de que se aceptase una nueva discusión sobre exclusión de prueba por parte del tribunal de juicio oral en lo penal, lo que en definitiva se estaría admitiendo sería la existencia de una suerte de apelación sui generis, en contra de la resolución previamente dictada por el juez de garantía en la audiencia de preparación. Ello daría pie a una (inadmisible) segunda revisión global de la prueba, esta vez por parte del tribunal de juicio oral, poniendo en entredicho la estructura misma de exclusión probatoria consagrada por el legislador y asignando con ello atribuciones al tribunal de juicio oral que exceden el ámbito de su competencia.

En nuestro sistema, las posibilidades otorgadas a los intervinientes de recurrir contra el auto de apertura del juicio oral, se limitan a lo estipulado en el art. 277 inc. $2^{\circ} \mathrm{CPP}$ que permite la interposición de un recurso de apelación por parte del ministerio público, para impugnar la exclusión de prueba decretada por el juez de garantía. ${ }^{55}$ Encontrándose firme el auto de apertura, las posibilidades de impugnación de los intervinientes por inclusión o exclusión indebida de un elemento de prueba, se limitarán a la eventual interposición de un recurso de nulidad (art. 277 inc. $2^{\circ}$, parte final en relación a lo dispuesto en los arts. 372 y ss. CPP), previo cumplimiento de los requisitos de procedencia del mismo.

\footnotetext{
${ }^{53}$ Cfr. CERDA SAN MARTIN, "La prueba lícita“, cit. nota n 1, p. 148; HORVITZ LENNON, LOPEZ MASLE, Derecho procesal penal, cit. nota $\mathrm{n}^{\circ} 1$, p. 197.

${ }^{54}$ Corte Suprema, sentencias ingresos Nr. 1496-03 (Cons. 14 ${ }^{\circ}$ ); 5154-04 (Cons. $2^{\circ}$ ); 5869-04 (Cons. $4^{\circ}$ ); $3666-05$ $\left(\right.$ Cons. $\left.4^{\circ}\right) ; 2521-08\left(\right.$ Cons. $\left.13^{\circ}\right)$; 3016-11 (Cons. $7^{\circ}$ ). En la literatura vid. DONOSO BOASSI, Samuel, "Prueba ilícita, oportunidad para debatir y resolver sobre la regla de exclusión”, Revista Derecho Mayor Nr. 7 (2008), pp. $35-42$, p. 39.

${ }^{55}$ Cabe señalar al respecto que el Tribunal Constitucional ha declarado en algunas sentencias (Ingresos Nr. 15022010, 1535-2010, 2628-2010 y 3452-2017) la inconstitucionalidad del art. 277 CPP en lo referido a la oración "cuando lo interpusiere el Ministerio Público", abriendo de este modo la puerta a otros intervinientes, para impugnar el auto de apertura del juicio oral por defectos en el pronunciamiento del juez sobre la exclusión de prueba. En contra, ingresos Nr. 2330-2013, 2354-2014, 2323-2014 y 2615-2014, en los cuales el Tribunal Constitucional ha rechazado declarar la inaplicabilidad por inconstitucionalidad del precepto referido.
} 
162 CORREA, Carlos. "Más Más allá de la regla de exclusión: prohibiciones probatorias

en el Derecho chileno - con especial referencia al Derecho alemán -".

La respuesta negativa a discutir nuevamente una exclusión de prueba en la audiencia de juicio oral, no implica extender dicha conclusión a la pregunta respecto de la valoración por parte del tribunal de juicio oral, de aquellos elementos probatorios erróneamente incorporados en el auto de apertura. A esto nos abocaremos en las líneas que siguen.

\subsection{Prohibiciones de valoración de prueba en la audiencia de juicio oral}

A este respecto, se ha discutido en Chile la posibilidad de que el tribunal de juicio oral prescinda de la valoración de aquellos elementos probatorios que, pese a haber sido (erróneamente) admitidos en la audiencia de preparación de juicio oral, fueron obtenidas con inobservancia de garantías fundamentales.

Para López ${ }^{56}$, la respuesta a la pregunta previamente planteada es negativa: el tribunal de juicio oral debe necesariamente, en todos los casos y sin excepción alguna, valorar la totalidad de la prueba rendida en juicio, independiente del origen de la misma. Para justificar dicha posición, otorga el autor diversos argumentos.

En primer término sostiene que admitir la posibilidad de negar valor a un medio de prueba previamente admitido por el juez de garantía importaría comprometer la "estructura de la prueba ilícita en el proceso penal chileno". ${ }^{57}$ De este modo, reconocer dicha posibilidad importaría "desconocer la responsabilidad privativa de los jueces de garantía en el control de la prueba ilícita". Admitir la no valoración de prueba erróneamente incorporada conllevaría, por razones calificadas por el autor de "exigencia de una buena praxis profesional", la necesidad de renovar la discusión sobre exclusión de prueba, ahora ante el tribunal de juicio oral. Aceptado lo anterior, se produciría un debilitamiento de las funciones del juez de garantía, transfiriendo el control de admisibilidad de la prueba, finalmente, al tribunal de juicio oral en lo penal con los evidentes perjuicios económicos y sistémico-estructurales que ello implica.

En segundo lugar, sustenta López la imposibilidad de no valorar prueba por parte del tribunal de juicio oral, en la inexistencia de una norma de carácter general que autorice a dicho tribunal a "suprimir la valoración de la prueba rendida", en base a su ilicitud. ${ }^{58}$

El último argumento esgrimido por el autor, se basa en lo dispuesto en el art. 277 inc. $2^{\circ} \mathrm{CPP}$, disposición que limita las posibilidades de impugnación en materia de exclusión de prueba en primer término al recurso de apelación (exclusivamente para el ministerio público por exclusión de prueba decretada por el juez) o bien al recurso de nulidad interpuesto por cualquiera de los intervinientes en contra de la sentencia definitiva que valoró prueba erróneamente admitida en la audiencia de preparación.

Como corolario de su argumentación, admite López que su posición llevará al juez a dictar sentencia "muy a su pesar", 59 en base a prueba obtenida con infracción de garantías fundamentales, situación que sólo podrá ser remediada por el tribunal que conozca del recurso de nulidad interpuesto en contra de la sentencia.

Sin perjuicio de los argumentos enunciados, y contradiciendo parcialmente su tesis principal, de manera excepcional acepta López la posibilidad por parte del tribunal de juicio oral de

\footnotetext{
${ }^{56}$ HORVITZ LENNON, LOPEZ MASLE, Derecho procesal penal, cit. nota ${ }^{\circ} 1$, pp. 200 y ss. En este sentido, vid. ECHEVERRIA DONOSO, Los derechos fundamentales, cit. nota $\mathrm{n}^{\circ} 39$, pp. 72 y ss.

${ }^{57}$ HORVITZ LENNON, LOPEZ MASLE, Derecho procesal penal, cit. nota ${ }^{\circ} 1$, pp. 200 y ss.

${ }^{58}$ HORVITZ LENNON, LOPEZ MASLE, Derecho procesal penal, cit. nota $\mathrm{n}^{\circ} 1$, pp. 201 y s.

${ }^{59}$ HORVITZ LENNON, LOPEZ MASLE, Derecho procesal penal, cit. nota ${ }^{\circ} 1$, p. 203.
} 
Polít. crim. Vol. 13, N 25 (Julio 2018) Art. 4, pp. 144-174.

[http://www.politicacriminal.cl/Vol_13/n_25/Vol13N25A4.pdf]

desestimar prueba previamente admitida, exclusivamente en base a la "poca o nula credibilidad", que ésta -en base a su origen- genere. Una obtención probatoria ilegal, que afecte la credibilidad del medio de prueba cuestionado, podría en estos casos llevar al tribunal en definitiva a no valorar el elemento cuestionado. ${ }^{60}$ Como se analizará posteriormente, dicha excepción parcial resulta insuficiente para garantizar un adecuado respeto de las garantías del imputado en el proceso penal y atiende igualmente a criterios arbitrarios, difícilmente justificables.

La postura contraria ha sido asumida en nuestra doctrina por Hernández, ${ }^{61}$ autor que postula que el tribunal de juicio oral no debe valorar aquellos elementos de prueba obtenidos mediante vulneración de garantías fundamentales, erróneamente introducidos al auto de apertura del juicio oral.

Para Hernández, el art. 276 CPP cumple en nuestro sistema una función de "prohibición general de valoración de prueba obtenida con infracción de garantías fundamentales", prohibición que se extendería incluso respecto del tribunal llamado a valorar la prueba, como lo es el tribunal de juicio oral. ${ }^{62}$ De este modo, cuando el juez de garantía erróneamente no excluye prueba ilícitamente obtenida, el tribunal de juicio oral se encuentra imposibilitado de valorar dicha prueba; de lo contrario -afirma el autor- el juez se encontraría obligado a fallar, conscientemente, basado en una vulneración de garantías. ${ }^{63}$

Como se explicó supra, el juez de tribunal oral se encuentra obligado (por regla general y salvo las excepciones puntuales referidas) a admitir que la prueba incorporada al auto de apertura sea -independiente de su origen- rendida en el juicio oral. Sostener lo contrario importaría, como se señaló oportunamente, una transgresión en las potestades concedidas al tribunal de juicio oral, atribuyéndose en este punto facultades exclusivas del juez de garantía.

Dicha conclusión no implica, sin embargo, que el origen del medio de prueba admitido deba ser irrelevante para el tribunal de juicio oral. Por el contrario, en aquellos casos en los cuales el juez de tribunal oral de oficio o bien por medio de los intervinientes advierte que la prueba ofrecida fue obtenida vulnerando garantías fundamentales, deberá prohibir que dicho medio de prueba sea valorado en la sentencia definitiva. Para tales efectos, deberá el tribunal indicar en la sentencia las razones por las cuales llegó a tal conclusión.

En este sentido, podemos sostener que las hipótesis de exclusión de prueba expresamente reconocidas por el legislador, paradigmáticamente en el art. 276 inc. $3^{\circ} \mathrm{CPP}$, no agotan el tratamiento de la llamada prueba ilícita en nuestro ordenamiento procesal penal. Por el contrario, la existencia de prohibiciones probatorias en el derecho chileno surge como regla residual de resguardo de garantías fundamentales más allá del alcance de la regla de exclusión, respecto de casos no reconocidos por ésta. Y será precisamente allí donde el modelo de prohibiciones probatorias dependientes desarrollado en Alemania a partir de las investigaciones llevadas a cabo por Beling hace más de 100 años resulta aplicable en Chile.

El modelo Alemán antes descrito, tiene la ventaja de permitir un análisis por parte del juez con competencia en lo criminal, respecto de la valoración o no valoración de la prueba en virtud de

\footnotetext{
${ }^{60}$ HORVITZ LENNON, LOPEZ MASLE, Derecho procesal penal, cit. nota ${ }^{\circ}$ 1, p. 204.

${ }^{61}$ En un sentido similar, DONOSO BOASSI, "Prueba ilícita", cit. nota ${ }^{\circ}$ 54, pp. 39 y ss.; HERNANDEZ BASUALTO, Héctor, Prueba ilícita y recurso de nulidad: (o ¿Para qué está la Corte Suprema). GJ t. 332 (2008), pp. 60-68, p. 60, nota al pie n ${ }^{\circ} 3$; HERNANDEZ BASUALTO, Exclusión, cit. nota n ${ }^{\circ}$ 1, pp. 89 y ss.

${ }^{62}$ HERNANDEZ BASUALTO, Exclusión, cit. nota n ${ }^{\circ}$ 1, p. 90.

${ }^{63}$ HERNANDEZ BASUALTO, Exclusión, cit. nota n ${ }^{\circ}$, p. 90.
} 
164 CORREA, Carlos. "Más Más allá de la regla de exclusión: prohibiciones probatorias

en el Derecho chileno - con especial referencia al Derecho alemán -".

la vulneración a una regla de obtención probatoria aún a falta de una regla expresa que regule el tratamiento de la prueba en el proceso penal atendido su origen. Su aplicación a los casos no cubiertos por la regla de exclusión ya mencionados, resulta del todo pertinente.

\section{Fundamento legal de las prohibiciones probatorias en el Derecho chileno}

El deber del juez de fondo de valorar negativamente los elementos de prueba cuestionados en relación a la forma en la cual fueron obtenidos, encuentra sustento material en el derecho chileno en lo dispuesto en el art. 297 CPP, disposición que consagra una obligación para el juez, de hacerse cargo en su fundamentación, de toda la prueba rendida "incluso de aquella que hubiere desestimado", caso en el cual deberá el tribunal indicar las razones que motivaron tal decisión.

La disposición referida importa un deber para el juez en orden a analizar en su sentencia la totalidad de la prueba rendida en juicio, sin que de ello se derive necesariamente una obligación para el tribunal de valorarla positivamente. La posibilidad expresa consagrada por el legislador al juez en orden a permitirle desestimar determinados medios de prueba se extiende no sólo a defectos que pudiese adolecer la prueba en relación a su credibilidad-v.gr. art. 309 inc. $1^{\circ} \mathrm{CPP}-$ sino además a posibles cuestionamientos fundados en vicios en su obtención que atenten finalmente en su idoneidad para lograr la convicción del tribunal.

Adicionalmente, la posibilidad de no valorar judicialmente un determinado medio de prueba en virtud de su origen, se enmarca además dentro de la prohibición general de valorar aquellos medios de prueba obtenidos mediante vulneración de garantías fundamentales. Esta se sustenta en la obligación de todo órgano del Estado (establecida en el artículo $6^{\circ}$ inc. $1^{\circ}$, en relación al art. $5^{\circ}$ inc. $2^{\circ}$ de la Constitución Política) de someter su actuar al resguardo de los Derechos Fundamentales establecidos en la Constitución y Tratados Internacionales.

\subsection{Insuficiencia del recurso de nulidad como remedio procesal respecto de la prueba erróneamente admitida}

La justificación esgrimida por López para rechazar la solución aquí expuesta, basada en la posibilidad (desde luego, eventual) de recurrir de nulidad en contra de la sentencia definitiva, constituye una respuesta en extremo formalista que no resuelve adecuadamente el problema referido al tratamiento de la prueba erróneamente admitida por parte del tribunal de juicio oral.

Contrario a lo sostenido por dicho autor, la posibilidad contemplada en el art. 277 inc. $2^{\circ} \mathrm{CPP}$ de interponer un recurso de nulidad a partir de una errónea admisión de prueba, no constituye una justificación suficiente para permitir al tribunal de juicio oral fundamentar una condena en prueba obtenida con infracción de garantías. A este respecto, no resulta admisible que un juez resuelva conscientemente en base a prueba obtenida con infracción de garantías aduciendo una supuesta imposibilidad fáctica de resolver en otro sentido.

El juez no debe en caso alguno valorar dicha prueba, pues al hacerlo estará basando conscientemente- su condena en una infracción de garantías, incumpliendo su deber constitucional de sometimiento a la Constitución antes referido, actuando además en contravención al principio de buena fe procesal.

Dicho lo anterior, resta por descartar la validez del contraargumento residual esgrimido por López, para justificar sólo parcialmente una prohibición de valoración de prueba, limitada a aquellos casos en los cuales la prueba adolezca de falta de credibilidad. 
El criterio delimitador esgrimido por el legislador en el art. 276 inc. $3^{\circ} \mathrm{CPP}$ para excluir elementos de prueba de la etapa del juicio oral se basa en una obtención de los mismos que resulta atentatoria contra garantías fundamentales. Con ello, el legislador ha tomado una decisión político criminal, que descarta razones adicionales para excluir prueba, como podrían serlo por ejemplo, consideraciones referidas a la credibilidad o falta de credibilidad del medio de prueba ${ }^{64} \mathrm{El}$ criterio sostenido por López, carece -por un lado- de suficiente sustento legal y además, contradice la voluntad del legislador, en orden a establecer como criterio único de exclusión de prueba una vulneración de garantías.

Sin perjuicio de lo anterior, puede sostenerse además que en la práctica, sólo una parte ínfima de aquellos medios de prueba obtenidos en infracción a reglas de obtención de prueba, generarán dudas respecto de la veracidad de su contenido. Ello sucederá paradigmáticamente, respecto de aquella prueba personal obtenida mediante coacción o amenazas, en la cual la veracidad de las declaraciones obtenidas utilizando -paradigmáticamente- métodos de interrogatorio prohibidos, pudiese ser puesta en duda. Sin embargo, en la mayoría de los casos (pensemos por ejemplo, en aquella prueba incautada de un domicilio sin contar con los requisitos establecidos en la ley para ingresar al recinto) la credibilidad del medio de prueba obtenido no resultará per sé cuestionable.

En definitiva, en un Estado de Derecho, enfrentado sea el juez del fondo a prueba en cuya obtención fueron vulneradas garantías fundamentales (haya sido esto discutido previamente o no al momento de tratar la admisión de la prueba en la audiencia de preparación del juicio oral) no resulta exigible al órgano adjudicador, tener que fallar a todo evento valorando positivamente dicha prueba ilícitamente obtenida. La solución aquí propuesta le ofrece al juez del fondo una salida, permitiéndole finalmente excluir de su valoración aquella prueba obtenida ilícitamente, debiendo en todo caso fundamentar en su resolución las razones que conducen a ello.

Entre ambas posiciones contrapuestas, parece ser la última aquella que razonablemente dota de mayor legitimidad a una sentencia definitiva, requisito siempre necesario para la imposición de una sanción penal.

\subsection{Criterio material de determinación de prohibiciones de valoración de prueba en el derecho chileno}

Aceptada la existencia residual de prohibiciones de valoración de prueba en el proceso penal chileno, resta por responder la pregunta acerca del criterio material de determinación de éstas, esto es -tal como se ha discutido incesantemente en el derecho alemán- aquellos criterios materiales que permitan distinguir entre infracciones a reglas de producción de prueba que generarán una prohibición de valoración de la prueba, de aquellas que no.

En este sentido, se podría eventualmente argumentar, siguiendo a la doctrina mayoritaria en Alemania, que el juez deberá tomar su decisión en los casos no comprendidos dentro del alcance de la regla de exclusión, a partir de una ponderación de intereses entre una eficiente persecución penal, y el resguardo de las garantías del imputado. Igualmente, podría teóricamente plantearse como criterio delimitador para el derecho chileno el llamado fin de protección de la norma, excluyendo de la valoración sólo aquellos medios de prueba obtenidos mediando una infracción

\footnotetext{
${ }^{64}$ Una postura crítica de la llamada "credibilidad del medio de prueba" como fundamento de la exclusión de prueba se encuentra en NUÑEZ OJEDA, CORREA ZACARIAS, “La prueba ilícita”, cit. nota n 38, p. 217.
} 
166 CORREA, Carlos. "Más Más allá de la regla de exclusión: prohibiciones probatorias en el Derecho chileno - con especial referencia al Derecho alemán -".

de aquellas reglas de obtención probatoria, cuyo ethos traería aparejado una imposibilidad de valorar la prueba así obtenida.

La respuesta a la pregunta antes planteada, respecto del derecho chileno, se encuentra en el motivo de exclusión de prueba contemplado en el art. 276 inc. $3^{\circ}$ parte final CPP; la infracción de garantías fundamentales constituye el criterio entregado por el legislador al juez para proceder a la exclusión de prueba con motivo de su obtención y como tal, debe servir además como elemento delimitador para distinguir entre obtenciones ilegales de prueba impunes, de aquellas que darán lugar a una prohibición de valoración. La decisión adoptada por el legislador en el art. 276 inc. $3^{\circ} \mathrm{CPP}$ se enmarca en una opción político criminal, ${ }^{65}$ vinculante asimismo para el juez al momento de adoptar decisiones fuera de la audiencia de preparación, referidas a la valoración o prohibición de valoración de un determinado medio de prueba.

Consideraciones adicionales al criterio referido, no desempeñan ni pueden desempañar ningún papel ni en materia de exclusión (por mandato expreso del legislador), ni de prohibición de valoración de prueba. En este entendido, la causal es objetiva, y deberá ser aplicada indistintamente, sin atender a criterios de ponderación de intereses referidos paradigmáticamente, a la gravedad del delito investigado.

En caso de aceptar consideraciones adicionales para rechazar o aceptar una prohibición de valoración -fuera de la infracción de garantías-, se daría lugar a inconsistencias internas, dando paso a asimetrías en la actuación de jueces, que repercutirían directamente en la protección conferida por el legislador a las garantías fundamentales en el proceso penal.

Ahora bien, la infracción de garantías como criterio delimitador de obtenciones no debe entenderse de modo tal que cualquier vulneración a una regla procedimental vinculada a una obtención de prueba, dará necesariamente paso a una prohibición de valoración. Infracciones contra reglas procesales, que no impliquen directamente una vulneración de garantías (por ejemplo, el incumplimiento por parte del fiscal o la policía, de las obligaciones de protocolización e inventario establecidas en los arts. 205 inc. $2^{\circ}, 206$ inc. $2^{\circ}$ o 221 inc. $2^{\circ} \mathrm{CPP}$ ) no darán origen a una prohibición de valoración de prueba (ni tampoco desde luego, a una exclusión de la misma ${ }^{66}$ ), sino exclusivamente a sanciones de otra índole, paradigmáticamente administrativas.

\section{3. ¿Renovación de la discusión sobre exclusión de prueba? Dificultades prácticas para cuestionar la obtención probatoria en la audiencia de juicio oral}

Aceptada la posibilidad de reconocer residualmente prohibiciones probatorias en el proceso penal chileno, cabe por último preguntarse de que manera la eventual discusión que al respecto se suscite en la etapa de juicio oral, no importa una renovación encubierta de la discusión -ya finalizada- sobre la exclusión de la prueba.

Como ya se esbozó, la posibilidad de generar una incidencia especial durante el desarrollo de la audiencia de juicio oral, destinada a impugnar el origen de un determinado medio de prueba, se encuentra por regla general vedada. Ella implicaría necesariamente discutir nuevamente un asunto ya resuelto. Sin perjuicio de ello, estimamos que las posibilidades de impugnar la

\footnotetext{
${ }^{65}$ Así, la infracción de garantías, como criterio delimitador de infracciones mira exclusivamente el interés del afectado, más no el interés del Estado en una eficiente averiguación de la verdad.

${ }^{66}$ Cfr. NUÑEZ OJEDA, CORREA ZACARIAS, "La prueba ilícita”, cit. nota n 38, p. 214.
} 
Polít. crim. Vol. 13, № 25 (Julio 2018) Art. 4, pp. 144-174.

[http://www.politicacriminal.cl/Vol_13/n_25/Vol13N25A4.pdf]

valoración futura de un medio de prueba atendido el origen del mismo, si bien mermada por las razones referidas, no deviene necesariamente en una probatio diabólica.

Al respecto, cabe tener presente que la incorporación (errónea) de un medio de prueba ilícitamente obtenido en el auto de apertura no necesariamente importa un defecto cometido por el tribunal en la etapa de preparación del juicio oral.

En efecto, en muchos casos el origen ilícito de un determinado medio de prueba será conocido por los intervinientes recién en la audiencia de juicio oral, esto es al momento en que la prueba es rendida. Pensemos por ejemplo el caso de un policía, que dando cuenta en el juicio oral de los hechos que motivaron su ingreso a un domicilio (dentro del cual, supongamos, incautó documentos), describe una situación de hecho hasta entonces desconocida que no se ajusta a alguna de las hipótesis consagradas por el legislador para a autorizar un ingreso sin orden judicial.

En estos casos, deberá el abogado defensor durante el transcurso del juicio oral, o bien al presentar sus alegatos de clausura, hacer mención a la ilicitud de la obtención probatoria. No obstante, aún en ausencia de una alegación formal de parte del defensor en este sentido, puede el tribunal de oficio, atendido el mérito de los hechos narrados, privar de valoración a aquellos medios de prueba obtenidos en contravención con garantías.

En la situación inversa, esto es, en aquellos casos en los cuales la obtención atentatoria de garantías fue previamente discutida en la audiencia de preparación del juicio oral y fue posteriormente rechazada la exclusión por el juez de garantía, reiteramos que no resulta posible plantear un incidente especial destinado exclusivamente a renovar una discusión pasada. Desechada dicha alternativa, la exposición de un posible vicio en la obtención de un determinado medio de prueba se limitará a las posibilidades de actuación de los intervinientes contempladas en la audiencia de juicio oral. Así, por ejemplo, al momento de interrogar a un testigo cuya identidad supuestamente fue obtenida a partir de una vulneración de garantías, deberá el defensor - de conformidad a lo dispuesto en el art. 309 inc. $1^{\circ} \mathrm{CPP}$ - dirigirle preguntas destinadas a acreditar dicho vicio, fundamentado en la existencia de un defecto de idoneidad de la prueba. Constatado el vicio de origen, deberá asimismo el defensor -sin perjuicio, reiteramos, de las facultades del tribunal de restar de oficio valor a la prueba- hacer notar dichos antecedentes en sus alegatos de clausura, solicitando la prohibición de valoración de uno o más medios de prueba ilícitamente obtenidos o bien, vinculados causalmente con una infracción de garantías.

\section{Conclusiones}

En el procedimiento ordinario, la audiencia de preparación del juicio oral constituye, por regla general, la única oportunidad procesal para discutir la admisión o exclusión de la prueba ofrecida en la acusación. Excepcionalmente, dicha posibilidad se extiende a la etapa de juicio oral, limitada a las hipótesis excepcionales establecidas en los artículos 334 inc. $2^{\circ}$ y 336 CPP.

Enfrentado el juez de garantía en la etapa de investigación, o el tribunal de juicio oral, en la etapa de juicio, a material probatorio obtenido con infracción de garantías, deberá fundar su decisión excluyendo de su valoración dichos elementos de prueba. Lo anterior no constituye una simple posibilidad para el juez, sino una verdadera obligación para éste, fundamentada en el respeto por las garantías fundamentales y la coherencia interna del sistema. 
168 CORREA, Carlos. "Más Más allá de la regla de exclusión: prohibiciones probatorias en el Derecho chileno - con especial referencia al Derecho alemán -".

Dicha obligación, da origen al reconocimiento en nuestro sistema de prohibiciones de valoración de prueba dependientes. En este sentido, tal como sucede en el derecho alemán, rige en el ordenamiento chileno una concepción unitaria de prohibiciones de prueba, siendo éstas reconocidas en distintas etapas del procedimiento.

El contenido material de las prohibiciones de prueba en el derecho chileno está definido -de manera análoga- por el art. 276 inc. $3^{\circ}$ parte final CPP, que consagra la inobservancia de garantías fundamentales con motivo de la obtención probatoria, como criterio material de exclusión de prueba.

La solución aquí propuesta se fundamenta en último término en la finalidad perseguida por el proceso penal, en tanto reflejo de la tensión inherente entre la correcta averiguación de la verdad y el respeto por las garantías del imputado. Sin este último componente, la aplicación de una sanción por parte de un tribunal con competencia en lo penal se convertiría en un mero ejercicio despótico del poder, carente de legitimidad: la verdad en el derecho no es un valor que pueda ser alcanzado a cualquier precio. 
Polít. crim. Vol. 13, № 25 (Julio 2018) Art. 4, pp. 144-174.

[http://www.politicacriminal.cl/Vol_13/n_25/Vol13N25A4.pdf]

\section{Bibliografía}

ALSBERG, Max; NÜSE, Karl-Heinz; DALLMEYER, Jens, Der Beweisantrag im Strafprozess, 6a Ed., Köln: Heymanns, 2016.

AMELUNG, Knut, Informationsbeherrschungsrechte im Strafprozess, Berlin: Duncker \& Humblot, 1990.

AMELUNG, Knut, "Subjektive Rechte in der Lehre von den strafprozessualen Beweisverboten", en: SCHULZ, Joachim, VORMBAUM, Thomas Festschrift für Günter Bemmann: zum 70. Geburtstag am 15. Dezember 1997, Baden-Baden: Nomos, 1997, pp. 504-523.

AMELUNG, Knut, "Grundfragen der Verwertungsverbote bei beweissichernden Haussuchungen im Strafverfahren”, NJW (1991), pp. 2533-2540

ARMENTA DEU, Teresa, "La verdad en el filo de la navaja (nuevas tendencias en materia de prueba ilícita)", Ius et Praxis, Vol. 13, nº 2 (2007), pp. 345-377.

BELING, Ernst, Die Beweisverbote als Grenzen der Wahrheitserforschung im Strafprozess: Sonderausgabe. 2. Ed., Darmstadt: Buchges, 1968.

BEULKE, Werner, "Beweiserhebungs- und Beweisverwertungsverbote im Spannungsfeld zwischen den Garantien des Rechtsstaates und der effektiven Bekämpfung von Kriminalität und Terrorismus", JURA t. 8 (2008), pp. 653-666.

BEULKE, Werner, "Hypothetische Kausalverläufe im Strafverfahren bei rechtswidrigen Vorgehen von Ermittlungsorganen", ZStW, t. 41 (1991), pp. 657-680.

BLOMEYER, Jürgen, "Die Revisibilität von Verfahrensfehlern im Strafprozeß”, $J R$ t. 4, (1971), pp. 142-150.

BOFILL GENZSCH, Jorge, Die Beweisverbote im chilenischen Strafprozess, FriedrichAlexander-Universität zu Erlangen-Nürnberg, inédito, 1988.

CAROCCA PÉREZ, Alex, "Una primera aproximación al tema de la prueba ilícita en Chile", Ius et Praxis, vol. $4 \mathrm{~N}^{\circ} 2$ (1998), pp. 301-322.

CERDA SAN MARTIN, Rodrigo, "La prueba ilícita y la regla de exclusión”, Revista de la justicia penal, $\mathrm{N}^{\circ} 6$ (2010), pp. 99-176

DALAKOURAS, Theoharis, Beweisverbote bezüglich der Achtung der Intimsphäre: unter besonderer Berücksichtigung der Grundrechtsproblematik sowie des griechischen Rechts, Berlin: Duncker \& Humblot, 1988.

DALLMEYER, Jens, Beweisführung im Strengbeweisverfahren. $2^{\mathrm{a}}$ Ed., Norderstedt: Books on demand GmbH, 2008.

DENCKER, Friedrich, "Über Heimlichkeit, Offenheit und Täuschung bei der Beweisgewinnung im Strafverfahren - Anmerkungen aus Anlaß zweier Entscheidungen des BGH”, StV t. 5 (1994), pp. 667-683. 
170 CORREA, Carlos. "Más Más allá de la regla de exclusión: prohibiciones probatorias en el Derecho chileno - con especial referencia al Derecho alemán -".

DENCKER, Friedrich, Verwertungsverbote im Strafprozeß: ein Beitrag zur Lehre von den Beweisverboten, Köln; München y otros: Heymann, 1977.

DIAZ GARCIA, Luis, "Derechos fundamentales y prueba ilícita en el nuevo proceso penal chileno", en: COLOMA CORREA, Rodrigo (Coord.), La prueba en el nuevo proceso penal oral, Santiago: Lexis Nexis, 2003, pp. 129-160

DONOSO BOASSI, Samuel, "Prueba ilícita, oportunidad para debatir y resolver sobre la regla de exclusión”, Revista Derecho Mayor, n 7 (2008), pp. 35-42.

ECHEVERRIA DONOSO, Isabel, Los derechos fundamentales y la prueba ilícita: con especial referencia a la prueba ilícita aportada por el querellante particular y por la defensa, Santiago: Eds. Jurídicas de Santiago, 2010.

EISENBERG, Ulrich, Beweisrecht der StPO: Spezialkommentar. 9a Ed., München: Beck, 2015 .

ENGLÄNDER, Armin, VOLK, Klaus, Grundkurs StPO, 8a Ed., München: Beck, 2013.

FEZER, Gerhard, Strafprozeßrecht, 2ª Ed., München: Juristischer Studienkurs, 1995.

FEZER, Gerhard, Grundfragen der Beweisverwertungsverbote, Heidelberg: C.F. Müller, 1995.

GÖSSEL, Karl Heinz, "Kritische Bemerkungen zum gegenwärtigen Stand der Lehre von der Beweisverboten im Strafverfahren”, NJW(1981), pp. 649-657.

GÖSSEL, Karl Heinz, "Verfassungsrechtliche Verwertungsverbote im Strafverfahren”, JZ, t. 8 (1984), pp. 361-364.

GROPP, Walter, "Zur Verwertbarkeit eigenmächtig aufgezeichneter (Telefon-) Gespräche Der Fall Schenk und die Lehre von den Beweisverboten”, StV t. 5/1989 (1989), pp. 216228.

GRÜNWALD, Gerald, Das Beweisrecht der Strafprozeßordnung, Baden-Baden: Nomos, 1993.

GRÜNWALD, Gerald, "Beweisverbote und Verwertungsverbote im Strafverfahren”, JZ t. 15/16 (1966), pp. 489-501.

HARTMANN, Arthur, SCHMIDT, Rolf, Strafprozessrecht: Grundzüge des Strafverfahrens, 4a Ed., Grasberg bei Bremen: Schmidt, Dr. Rolf Verlag, 2012.

HAUF, Claus-Jürgen, "Ist die "Rechtskreistheorie" noch zu halten? Eine neue Konzeption zur Frage von Verfahrensfehlern und Beweisverwertungsverboten", NStZ t. 10 (1993), pp. 457-462.

HENGSTENBERG, Achim, Die Frühwirkung der Verwertungsverbote: eine Untersuchung der Bedeutung der Beweisverwertungsverbote für die strafprozessualen Verdachtsbeurteilungen, Hamburg: Kovac, 2007. 
Polít. crim. Vol. 13, № 25 (Julio 2018) Art. 4, pp. 144-174.

[http://www.politicacriminal.cl/Vol_13/n_25/Vol13N25A4.pdf]

HERNANDEZ BASUALTO, Héctor, Exclusión de la prueba ilícita en el nuevo proceso penal chileno. 2a Reimpresión, Santiago: Universidad Alberto Hurtado, 2005.

HERNANDEZ BASUALTO, Héctor, Prueba ilícita y recurso de nulidad: (o ¿Para qué está la Corte Suprema), GJ, t. 332 (2008), pp. 60-68.

HORVITZ LENNON, María Inés; LOPEZ MASLE, Julián, Derecho procesal penal, Tomo II, Santiago: Jurídica de Chile, 2004.

JÄGER, Christian, Beweisverwertung und Beweisverwertungsverbote im Strafprozess, München: C.H. Beck, 2003.

JÄGER, Christian, "Beweiserhebungs- und Beweisverwertungsverbote als prozessuale Regelungsinstrumente im strafverfolgenden Rechtsstaat. Zugleich ein Beitrag zum 67. Deutschen Juristentag", GA t. 155 (2008), pp. 473-499.

JAHN, Matthias, "Beweiserhebungs- und Beweisverwertungsverbote im Spannungsfeld zwischen den Garantien des Rechtsstaates und der effektiven Bekämpfung von Kriminalität und Terrorismus", en:, Ständigen Deputation des deutschen Juristentages (Ed.), Verhandlungen des Siebenundsechzigsten Deutschen Juristentages: Erfurt 2008, Band I Gutachten. München: C.H. Beck, 2008, pp. C1-C128.

JAHN, Matthias, "Grundfragen und aktuelle Probleme der Beweisverwertung im Straf- und Steuerstrafverfahren", en: JAHN, KUDLICH, STRENG (Ed.), Strafrechtspraxis und Reform - Festschrift für Heinz Stöckel zum 70. Geburtstag, Berlin: Duncker \& Humblot, 2010, pp. 259-286.

KELNHOFER, Evelyn, Hypothetische Ermittlungsverläufe im System der Beweisverbote, Berlin: Duncker \& Humblot, 1994.

KINDHÄUSER, Urs, Strafprozessrecht, 4a Ed., Baden-Baden: Nomos, 2015.

KNAUER, Christoph, KUDLICH, Hans, SCHNEIDER, Hartmut, Münchener Kommentar zur Strafprozessordnung, München: Beck, 2014.

KNAUTH, Alfons, "Beweisrechtliche Probleme bei der Verwertung von Abhörmaterial im Strafverfahren" NJW (1978), pp. 741-745.

LÖWE, Ewald, ROSENBERG, Werner, ERB, Volker, ESSER, Robert, FRANKE, Ulrich, GRAALMANN-SCHEERER, Kirsten, HILGER, Hans, IGNOR, Alexander, GERBER, Friederike, Die Strafprozeßordnung und das Gerichtsverfassungsgesetz: Großkommentar, Berlin; New York: de Gruyter, 2016.

LUBIG, Sebastian, Beweisverwertungsverbote im Kartellverfahrensrecht der Europäischen Gemeinschaft, Baden-Baden: Nomos, 2008.

MATURANA MIQUEL, Cristián, MONTERO LÓPEZ, Raúl, Derecho Procesal Penal Tomo II, Santiago: Legal Publishing Chile, 2012.

MAUL, Heinrich; ESCHELBACH, Ralf, "Zur "Widerspruchslösung" von Beweisverbotsproblemen in der Rechtsprechung”, StraFo Mayo/Junio 1996, pp. 66-70. 
172 CORREA, Carlos. "Más Más allá de la regla de exclusión: prohibiciones probatorias en el Derecho chileno - con especial referencia al Derecho alemán -".

MERGNER, Tobias, Fernwirkung von Beweisverwertungsverboten, Tesis Doctoral. Universität Köln, inédita, 2005.

MEYER-GOßNER, Lutz: SCHMITT, Bertram, Strafprozessordnung: Gerichtsverfassungsgesetz, Nebengesetze und ergänzende Bestimmungen, 58. Ed. München: Beck, 2015.

MÜSSIG, Bernd, "Beweisverbote im Legitimationszusammenhang von Strafrechtstheorie und Strafverfahren”, GA t. 146 (1999), pp. 119-142.

NUÑEZ OJEDA, Raúl; CORREA ZACARIAS, Claudio, "La prueba ilícita en las diligencias limitativas de derechos fundamentales en el proceso penal chileno", Ius et Praxis, vol. $23 \mathrm{n}^{\circ} 1,2017$, pp. 195-246.

OSMER, Jan-Dierk, Der Umfang des Beweisverwertungsverbotes § 136a StPO, Tesis Doctoral, Universidad Hamburg, inédita, 1966.

OSSENBERG, Sarah, Die Fernwirkung im deutsch-U.S.- amerikanischen Vergleich: unter bedonderer Berücksichtigung der Funktionen der Beweisverwertungsverbote, Hamburg: Kovac, 2011.

PAULUS, Rainer, "Rechtsdogmatische Bemerkungen zum Urkundenbeweis in der Hauptverhandlung des Strafverfahrens", JuS t. 28 (1998), pp. 873-879.

PELZ, Christian, Beweisverwertungsverbote und hypothetische Ermittlungsverläufe, Tesis Doctoral, Universidad de München, inédito, 1993.

PETRY, Horst, Beweisverbote im Strafprozeß, Saarbrücken: Stoytscheff, 1970.

PITSCH, Christoph, Strafprozessuale Beweisverbote: eine systematische, praxisnahe und rechtsvergleichende Untersuchung unter besonderer Berücksichtigung des Steuerstrafverfahrens, der Zufallsfunde und der Fernwirkungsproblematik, Hamburgo: Kovac, 2009.

RANFT, Otfried, "Bemerkungen zu den Beweisverboten im Strafprozeß", en: SEEBODE, Manfred, Festchrift für Günter Spendel zum 70. Geburtstag a, 11. Juli 1992, Berlin y otros: De Gruyter, 1992, pp. 719-736.

RANSIEK, Andreas, "Rechtswidrige Ermittlungen und die Fernwirkung von Beweisverwertungsverboten", en: FAHL, MÜLLER, SATZGER, SWODOBA, Festschrift für Werner Beulke zum 70. Geburtstag, Heidelberg: Müller, 2015, pp. 949961.

REINECKE, Jan, Die Fernwirkung von Beweisverwertungsverboten, München: VVF, 1990.

ROGALL, Klaus, "Über die Folgen der rechtswidrigen Beschaffung des Zeufenbeweises im Strafprozeß”, JZ t. 19/1996 (1996), pp. 944-955.

ROGALL, Klaus, "Hypothetische Ermittlungsverläufe im Strafprozeß”, NStZ t. 9 (1988), pp. 385-393. 
Polít. crim. Vol. 13, № 25 (Julio 2018) Art. 4, pp. 144-174.

[http://www.politicacriminal.cl/Vol_13/n_25/Vol13N25A4.pdf]

ROGALL, Klaus, "Beweiserhebungs- und Beweisverwertungsverbote im Spannungsfeld zwischen den Garantien des Rechtsstaates und der effektiven Bekämpfung von Kriminalität und Terrorismus", $J Z \mathrm{n}^{\circ} 17$ (2008), pp. 818-830.

ROGALL, Klaus, "Beweisverbote im System des deutschen und des amerikanischen Strafverfahrensrechts", en: WOLTER, Jürgen; FEIGEN, Hanns W. (Ed.), Zur Theorie und Systematik des Strafprozeßrechts, Neuburg y otros: Hermann Luchterhand Verlag, 1995, pp. 113-160.

ROGALL, Klaus, Der Beschuldigte als Beweismittel gegen sich selbst: ein Beitrag zur Geltung des Satzes "Nemo tenetur seipsum prodere" im Strafprozeß, Berlin: Duncker \& Humblot, 1977.

ROGALL, Klaus, "Das Verwendungsverbot des § 393 II AO", en: HIRSCH, WOLTER, BRAUNS (Ed.), Festschrift für Günther Kohlmann, Köln: OVS Verlag Dr. Otto Schmidt, 2003, pp. 465-498.

ROGALL, Klaus, "Gegenwärtiger Stand und Entwicklungstendenzen der Lehre von den strafprozessualen Beweisverboten", ZStW t. 91 (1979), pp. 1-44.

ROGALL, Klaus, "Grund und Grenzen der "qualifizierten" Belehrung im Strafprozess", en: GEISLER, KRAATZ, KRETSCHMER, SCHNEIDER, SOWADA (Ed.), Festschrift für Klaus Geppert zum 70. Geburtstag am 10. März 2011, Berlin y otros: de Gruyter, 2011, pp. 519-547.

ROGALL, Klaus, "Grundsatzfragen der Beweisverbote", en: HÖPFEL, Frank; HUBER, Barbara (Ed.), Beweisverbote in Ländern der EU und vergleichbaren Rechtsordnungen, Exclusion of Evidence Within the EU and Beyond, Europäisches Kolloquium Wien, 18. - 20. September 1997, Freiburg i. Br.: Iuscrim, 1999, pp. 119-148.

RÖGER, Ralf, Die Verwertbarkeit des Beweismittels nach $\S 81$ a StPO bei rechtswidriger Beweisgewinnung, Frankfurt a.M.: Lang, 1994.

ROXIN, Claus, "Die Rechtsprechung des Bundesgerichtshofs zum Strafverfahrensrecht - Ein Rückblick auf 40 Jahre -“, en: JAUERNIG, Othmar, ROXIN, Claus, 40 Jahre Bundesgerichtshof: Festveranstaltung am 1. Oktober 1990 mit Ansprache des Präsidenten des Bundesgerichtshofes, Heidelberg: C.F. Müller, 1991, pp. 66-99.

RUDOLPHI, Hans-Joachim, “Die Revisibilität von Verfahrensmängeln im Strafprozeß”, $M D R$ t. 2 (1970), pp. 93-100.

SCHLOTHAUER, Reinhold, "Zur Bedeutung der Beweisverwertungsverbote im Ermittlungsund Zwischenverfahren", en: PRITTWITZ, BAURMANN, GÜNTHER, KUHLEN, MERKEL, NESTLER, SCHULZ, (Ed.), Festschrift für Klaus Lüderssen: zum 70. Geburtstag am 2. Mai 2002, Baden-Baden: Nomos, 2002, pp. 761-772.

SCHNEIDER, Hartmut, "Zur Berücksichtigung hypothetischer Ermittlungsverläufe in Fällen grob fehlerhafter Annahme von Gefahr im Verzug bei Wohnungsdurchsuchungen", NStZ, Sonderheft 2009 (2009), pp. 46-52. 
174 CORREA, Carlos. "Más Más allá de la regla de exclusión: prohibiciones probatorias en el Derecho chileno - con especial referencia al Derecho alemán -".

SCHÖNEBORN, Christian, "Die strafprozessuale Beweisverwertungsproblematik aus revisionsrechtlicher Sicht", GA t. 122 (1975), pp. 31-41.

SCHRÖDER, Svenja, Beweisverwertungsverbote und Hypothese rechtmäßiger Beweiserlangung im Strafprozeß, Berlin: Duncker \& Humblot, 1992.

STÖRMER, Rainer, Dogmatische Grundlagen der Verwertungsverbote: eine Untersuchung über die Strukturen strafprozessualer Verwertungsverbote unter dem Einfluss der Verfassung und der Grundsätze des öffentlichen Rechts, Marburg: Elwert, 1992.

STÖRMER, Rainer, "Strafprozessuale Verwertungsverbote in verschiedenen Konstellationen", JURA t. 8 (1994), pp. 621-628.

WEIGEND, Thomas, “Anmerkung zum Beschluss des LG Frankfurt v. 9.4.2003 - 5/22 Ks 3490 Js 230118/02”, StV t. 8 (2003), pp. 436-440.

WOHLERS, Wolfgang, "Verwertungs-, Verwendungs- und/oder Belastungsverbote - die Rechtsfolgenseite der Lehre von den Beweisverwertungsverboten", en: HERZOG, SCHLOTHAUER, WOHLERS (Ed.), Rechtsstaatlicher Strafprozess und Bürgerrechte: Gedächtnisschrift für Edda Weßlau. Berlin: Duncker \& Humbot, 2016, pp. 427-444.

WOLTER, Jürgen, "Repressive und präventive Verwertung tagebuchartiger Aufzeichnungen zugleich Besprechung der Tagebuch-Entscheidung des BVerfG-“ StV t. 29 (1990), pp. 175-180.

WOLTER, Jürgen, “Anmerkung zum Urteil des BGH vom 24.08.1983 NStZ 1984, 275 ff.”, $N S t Z$ t. 6 (1984), pp. 276-278.

ZAPATA GARCÍA, Francisca, La prueba ilícita, Santiago: Lexis Nexis, 2004. 